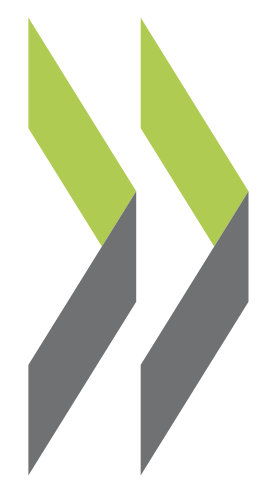

OECD Regional Development Working Papers 2019/09

Multi-level governance and cross-sector practices supporting the European Union Strategy

Maria Varinia Michalun, Alessandra Nicita

for the Adriatic and lonian Region 


\title{
Multi-level Governance and Cross- Sector Practices Supporting the European Union Strategy for the Adriatic and Ionian Region
}

\author{
By: Maria-Varinia Michalun and Alessandra Nicita
}

\begin{abstract}
European Union Strategy for the Adriatic and Ionian Region (EUSAIR) represents a long-term strategic policy framework to promote socio-economic growth and tighter relations between European Union member countries and countries in the Western Balkan region. Of the four European Union Strategies in place, EUSAIR is potentially the most challenging, with significant degrees of diversity among the four EU and four non-EU member partner countries. This is often revealed by their differences in administrative capacity, governance and economic development. National multi-level governance structures supporting EUSAIR contribute to the Strategy's national-level implementation. Enhancing the national multi-level governance practices applied to EUSAIR by participating countries could further build the Strategy's ability to contribute to national and macro-regional growth, development and environmental sustainability. This paper explores how questions of ownership, funding, strategic synergies, institutional coordination mechanisms, resource capacities and constraints, and stakeholder engagement affect EUSAIR implementation, and offers a series of recommendations for action.
\end{abstract}

JEL codes: O18, O19, R58

Keywords: EUSAIR; Multi-level Governance; Macro-region; Macro-regional Strategy; Western Balkans; Adriatic-Ionian; Regional Development

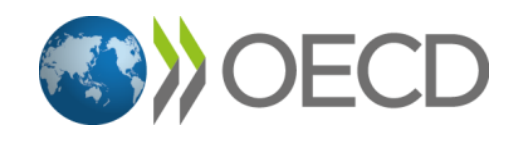




\section{ABOUT THE OECD}

The OECD is a multi-disciplinary inter-governmental organisation of 36 member countries, which engages an increasing number of non-members from all regions of the world. The Organisation's core mission today is to help governments work together towards a stronger, cleaner, fairer global economy. Through its network of 250 specialised committees and working groups, the OECD provides a setting where governments compare policy experiences, seek answers to common problems, identify good practice, and co-ordinate domestic and international policies. More information available: www.oecd.org.

This document, as well as any statistical data and map included herein, are without prejudice to the status of or sovereignty over any territory, to the delimitation of international frontiers and boundaries and to the name of any territory, city or area.

\section{ABOUT OECD REGIONAL DEVELOPMENT WORKING PAPERS}

Working papers from the Regional Development Policy Division of the OECD cover a full range of topics including regional statistics and analysis, urban governance and economics, rural governance and economics, and multi-level governance. Depending on the programme of work, the papers can cover specific topics such as regional innovation and networks, the determinants of regional growth or fiscal consolidation at the sub-national level. OECD Regional Development Working Papers are published on http://www.oecd.org/cfe/regional-policy.

OECD Working Papers should not be reported as representing the official views of the OECD or of its member countries. The opinions expressed and arguments employed are those of the author(s).

Working Papers describe preliminary results or research in progress by the author(s) and are published to stimulate discussion on a broad range of issues on which the OECD works. Comments on Working Papers are welcome, and may be sent to the Centre for Entrepreneurship, SMEs, Regions and Cities, OECD, 2 rue André-Pascal, 75775 Paris Cedex 16, France.

This paper is authorised for publication by Lamia Kamal-Chaoui, Director, Centre for Entrepreneurship, SMEs, Regions and Cities, OECD.

This publication was produced with the financial support of the European Union. Its contents are the sole responsibility of (name of the author/partner) and do not necessarily reflect the views of the European Union

(C) OECD 2019

You can copy, download or print OECD content for your own use, and you can include excerpts from OECD publications, databases and multimedia products in your own documents, presentations, blogs, websites and teaching materials, provided that suitable acknowledgement of OECD as source and copyright owner is given. All requests for public or commercial use and translation rights should be submitted to rights@oecd.org. 


\section{Acknowledgements}

This working paper was produced by the OECD Centre for Entrepreneurship, SMEs, Regions and Cities (CFE) led by Lamia Kamal-Chaoui, Director. It is part of the multilevel governance Programme of Work of the OECD's Regional Development Policy Committee.

It was written by Maria-Varinia Michalun from the OECD Secretariat, Decentralisation, Public Investment and Subnational Finance Unit in CFE, and Alessandra Nicita, independent expert on EU Cohesion policies, programming and evaluation, who synthesised individual case studies from each country, highlighting common themes, and providing expertise on EU Cohesion policy funding and management and the implications for EUSAIR. The report includes input from Dorothée Allain-Dupré and Yingyin Wu, from the OECD Secretariat.

The OECD EUSAIR National Governance Self-Assessment Tool associated with this working paper was developed by Maria-Varinia Michalun and Alessandra Nicita.

The paper was co-ordinated by Maria-Varinia Michalun, and supervised by Dorothée Allain-Dupré, Head of Unit, Decentralisation, Public Investment and Subnational Finance. This unit is in the Economic Analysis, Statistics and Multi-level Governance Section, led by Rudiger Ahrend, in CFE.

The authors gratefully acknowledge the comments and input received from EUSAIR National Coordinators, Pillar Coordinators, other EUSAIR Key Implementers from Albania, Bosnia-Herzegovina, Croatia, Greece, Italy, Montenegro, Serbia and Slovenia, as well as from the Facility Point Project Lead Partner and Facility Point Project Partners in participating countries and the European Commission's Unit for Macro-regions, Transnational, Interregional Cooperation, IPA, Enlargement (DG-REGIO). The comments received from the OECD Regional Development Policy Committee and colleagues in the OECD Global Relations Secretariat/South East Europe Programme, as well as insights from SIGMA colleagues are also gratefully acknowledged.

Thanks are also due to Pilar Philip who co-ordinated the production of the document and to François Iglesias for the cover art. 


\section{Table of contents}

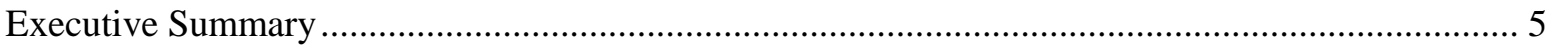

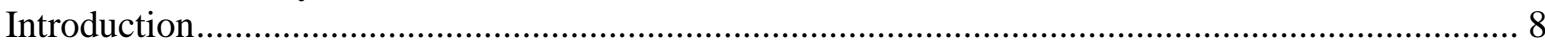

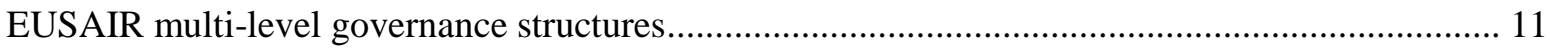

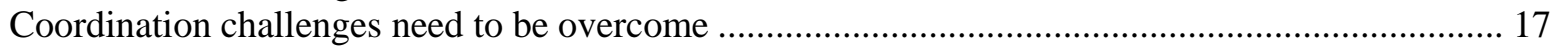

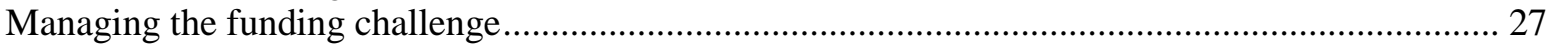

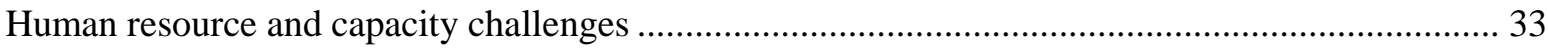

Strengthening links with EU, cross-border and national strategies and programmes........................ 34

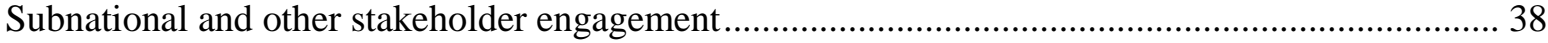

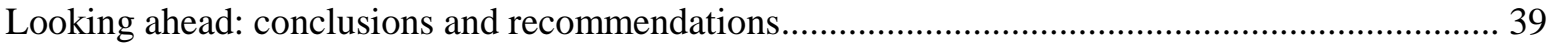

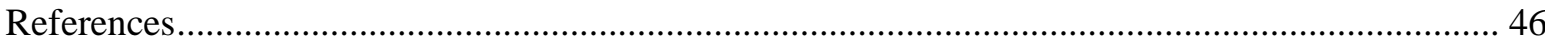

Annex A. A comparative table of actors involved by country and by pillar ................................. 55

\section{Tables}

Table 1. Overview of arrangements for EUSAIR implementation across central ministries 13

Table 2. Overview of arrangements for EUSAIR implementation across levels of government

\section{Figures}

Figure 1. EUSAIR National coordination structures and information flows within participating countries

Figure 2. EU Funds are the most turned to potential funding source

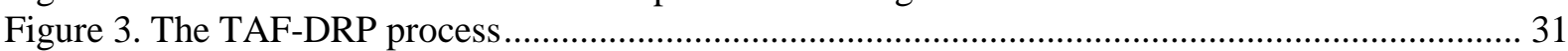

\section{Boxes}

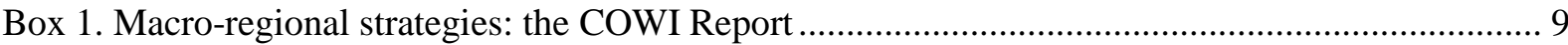

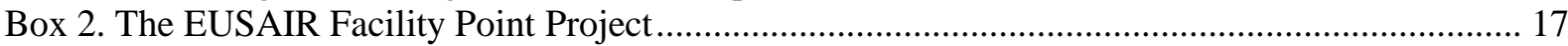

Box 3. Cross-sector and multi-stakeholder coordination in Sweden................................................... 19

Box 4. The Managing Authorities Network in the Baltic Sea Region ................................................. 22

Box 5. National level coordination and dialogue bodies in the Baltic Sea Region .............................. 23

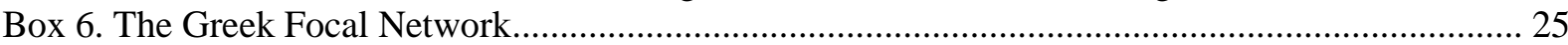

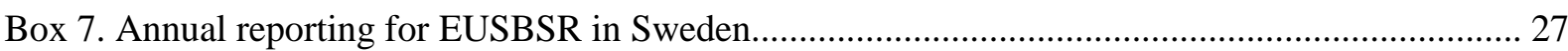

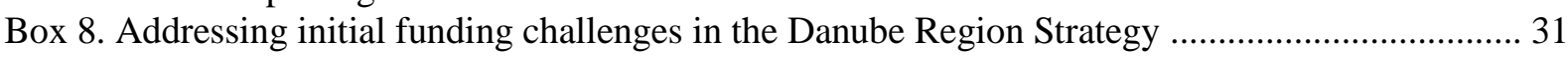

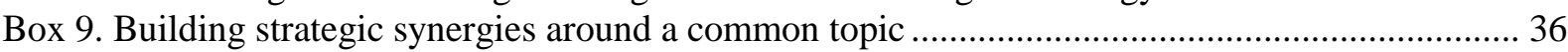

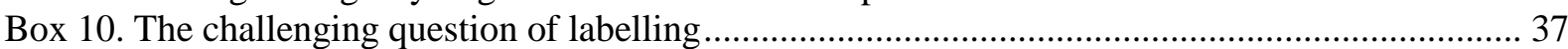

Box 11. Building awareness of EUSAIR at the subnational level in Albania, Greece and Slovenia.... 39

Box 12. Recommendations to support more effective multi-level governance of EUSAIR among all participating countries 


\section{Executive Summary}

The European Union Strategy for the Adriatic and Ionian Region (EUSAIR), adopted by the European Council in September 2014, represents a long-term strategic policy framework with two broad aims: to promote socio-economic growth, tighter relations between European Union members and countries in the Western Balkan region, while helping drive the EU enlargement and integration process; and to contribute to the economic development and social cohesion of its eight participating countries - Albania, Bosnia-Herzegovina, Croatia, Greece, Italy, Montenegro, Serbia and Slovenia - and the wider region. It focuses on common challenges in four thematic Pillars: Blue Growth, Connecting the Region (transport and energy), Environmental Quality, and Sustainable Tourism.

Of the four EU macro-regional strategies in place, EUSAIR is potentially the most challenging, with significant degrees of diversity among the four EU and four non-EU member partner countries. This is often revealed by their differences in administrative capacity, governance and economic development. National governance practices contribute directly and indirectly to the multi-level governance system applied to EUSAIR in each country, contributing to the Strategy's national-level implementation, and to its ability to contribute to growth, development and environmental sustainability in the region.

National multi-level governance structures supporting EUSAIR are in place. They are also unique and reflective of the differences in size, population, and history of the countries participating in EUSAIR, rendering de facto governance practices different. There are, however, six overarching areas where adjustments could be made to enhance the multilevel governance practices applied to EUSAIR by participating countries. Doing so could help further advance the Strategy's implementation now and in the future.

1. Building and maintaining a sense of ownership for EUSAIR through stronger cross-sector coordination is one of the largest challenges. In some cases, national governance cultures are top-down and siloed, in others there is limited incentive from the top to work in a cross-sector manner. In most countries, a lack of awareness of how EUSAIR can support national and sector objectives is another contributing factor. Government stakeholders (e.g. line ministries and subnational authorities), often need to better grasp the benefit of engaging with a macroregional strategy.

- Opportunities to help enhance ownership through stronger awareness include ensuring regular, clear and direct communication with stakeholders on the value-added of EUSAIR for national development goals; and developing national-level incentives to encourage cross-sector dialogue and cooperation across EUSAIR's four pillars.

2. Overcoming the funding obstacle to EUSAIR implementation. EUSAIR does not have an explicit or dedicated funding source. The intention was to permit countries to tap into both EU and national funding opportunities, but this has fallen 
short of expectation. In general, participants consider EU funding sources as the main potential financing mechanism for the Strategy. While a dedicated funding source is likely unnecessary, clearer support and guidance with respect to accessing existing funding would be beneficial.

- Opportunities to manage the funding challenge can include creating a practical, easy to use funding overview guide; introducing early funding tools; and promoting greater flexibility in accessing EU funds at the start of new programming periods.

3. Capitalising on the strong strategic synergies offered by EUSAIR requires ongoing support at the $\mathbf{E U}$ and national levels. The lack of direct ex ante links between EUSAIR and EU programming in EU-member countries and non-EU member countries is a serious challenge, and hinges on both timing and incentive. EUSAIR was adopted after EU strategic programming documents were negotiated. This generated a mismatch between EUAIR and mainstream framework programmes, compounded by limited incentive for mainstream programmes to incorporate EUSAIR initiatives. The net result is further limitations for EUSAIR to access funds. At national levels, explicitly embedding EUSAIR into national strategic, planning and framework documents has proven difficult, also often due to timing and incentive reasons.

- Opportunities to generate stronger strategic synergies between EUSAIR and national-level EU-programming or sector initiatives include identifying and focusing on large impact projects with multiplier effects; improving communication and information flows with other EU initiatives at the national programming level; and ensuring EUSAIR is integrated into the forthcoming negotiations for the post-2020 programming period.

4. Enhancing national EUSAIR multi-level governance structures and existing coordination mechanisms would contribute to stronger implementation capacity. Participants apply a logical but compartmentalised approach to multilevel governance for EUSAIR, resulting in information flows that tend to be vertical (i.e. top-down and bottom-up) rather than horizontal - across the four Pillars and throughout the multi-level governance chain (from European to subnational levels). Coordination mechanisms combine the formal with the informal and could be stronger, horizontally and vertically.

- Opportunities to address the multi-level governance structural challenges as well as the coordination challenges include a clearer attribution of responsibilities and expectations between EUSAIR and EU programming authorities in all participating countries; better harmonising expectations from distinct coordinating groups; breaking down silos within the pillar structures; holding regular national cross-sector EUSAIR meetings with key national and subnational actors; and developing stronger ties with peers in other macroregional strategies.

5. Ensuring human resource needs are met could increase capacity to advance EUSAIR. Many, if not all, participants experience limitations in ensuring consistent levels of experienced staff dedicated to EUSAIR. This can manifest in a turnover of qualified staff combined with difficult or lengthy processes to replace them, and/or in the number of officials and the amount of time dedicated to EUSAIR. 
- Opportunities to meet the challenges presented by limitations in human resources can include continued activity by the Facility Point Project to support shared learning and specific training and exchange; and strengthening the political commitment to ensure sufficient human resources for EUSAIR's implementation.

6. Integrating and engaging with subnational and non-government stakeholders is fundamental to EUSAIR's success as implementation occurs at the regional and local levels. Thus far, formal subnational-level involvement in the EUSAIR has been low (except in Greece and Italy where legal frameworks require nationalregional engagement). Participating countries generally agree that stronger mobilisation of subnational-level and non-government actors is necessary, which may become easier as the Strategy matures.

- Opportunities to generate stronger stakeholder engagement include incorporating a broad range of stakeholders in EUSAIR thematic discussions; sponsoring or collaborating in public awareness activities; and involving stakeholders in EUSAIR discussions related to the new programming period. 


\title{
Introduction
}

\begin{abstract}
Adopted by the European Council on 29 September 2014, the European Union Strategy for the Adriatic and Ionian Region (EUSAIR) represents a means to promote socio-economic growth and tighten relations between members of the European Union and countries in the Western Balkan region, while also serving as a mechanism to help drive the European Union's enlargement and integration process (European Parliament, 2018). As an integrated, long-term strategic policy framework it aims to help eight countries - Albania, Bosnia-Herzegovina, Croatia, Greece, Italy, Montenegro, Serbia and Slovenia - coordinate their policies and strategic investment plans, and co-operate in programmes and strategic projects. The goal is to contribute to the economic development and social cohesion of each country and the wider region by addressing common challenges and opportunities in four thematic areas: Blue Growth (Pillar 1), Connecting the Region (transport and energy) (Pillar 2), Environmental Quality (Pillar 3), and Sustainable Tourism (Pillar 4). Each pillar is coordinated by one EU and one non-EU member country. Capacity building, research and innovation and SME development run through all pillars as crosscutting themes.
\end{abstract}

\section{Contextual background}

Since its introduction in 2014, EUSAIR has had difficulty taking flight. While it is not the "youngest" of the macro-regional strategies, it is potentially the most challenging, with high degrees of diversity and disparities among the four EU and four non-EU member partnering countries. These differences are particularly noted in terms of administrative capacity, governance and economic development (COWI, 2017). As is the case with other macro-regional strategies, the strategy's implementation is framed around the " 3 No's": no new institutions, no new EU funding, and no new regulations. While this can afford high degrees of flexibility for participating countries in how they structure and implement their participation, it also creates difficulties. The fact that there are no binding procedures or arrangements or no specific funding mechanism can make it more difficult to ensure participation by government and non-government stakeholders, or easily identify value added, issues that will be explored throughout in this document. This last point, with respect to value added, is important and poses a significant challenge, especially as after three years there are few concrete results that can be attributed to the strategy and used to build support and ownership among stakeholders. This matter of limited concrete results appears very much in keeping with the development phases of macro-regional strategies (Box 1), as EUSAIR has not yet reached Phase III, and may be somewhere between Phases I and II, depending on the country. The challenge however, remains, and the specific Phase in which the strategy finds itself is difficult to explain to government and non-government stakeholders who are likely to have high expectations, and seek more immediate and more visible results. EUSAIR's governance and participation mechanisms still very much rely on the enthusiasm and commitment of the public officials contributing to it in each of the eight partner countries, within their capacity to do so. 


\section{Box 1. Macro-regional strategies: the COWI Report}

A 2017 study prepared by COWI at the request of the European Commission, and dedicated to all four macro-regional strategies, identified three conceptual phases of macro-regional strategy development:

- Phase I: relates to the capacity of the actors within the macro-regional strategy, generally at the individual level.

- Phase II: relates to the development of institutional capacity and performance of actors within the macro-regional strategy, and the individual and institutional capacity by external stakeholders to respond to the strategy.

- Phase III: relates to how external stakeholders and the region overall is performing - i.e. their implementation of relevant macro-regional actions, and their contribution to the integration and development of the region become visible through the achievement of macro-regional objectives.

Source: COWI (2017), Study on Macro-Regional Strategies and their Links with Cohesion Policy: Final Report, European Commission Directorate General Regional and Urban Policy, COWI, Kongens Lyngby, Denmark, available:

http://ec.europa.eu/regional_policy/sources/cooperate/adriat_ionian/pdf/eusair_links_cohesion_policy.pdf

Part of the multi-level governance challenge confronting the countries involved in EUSAIR arises from the strategy itself, its own governance mechanisms, and directly related implementation tools. Other aspects arise due to specific national contexts (explored in country notes provided to each participant). What is clear, however, is that in order to address these challenges, additional consideration will need to be given to funding mechanisms and how they are managed, strengthening connections with EU operational programmes, knowledge sharing and communication flows, horizontal and vertical coordination and cooperation. Capacity building in all areas, and at all levels, will be fundamental, as will learning from other macro-regional strategies and EUSAIR countries in their application of mainstream policies and programmes. At the same time, there is significant opportunity and margin for the strategy to be successful and to have an impact on the growth, development, and environmental sustainability of the Adriatic and Ionian region (European Parliament, 2018).

\section{EUSAIR governance structures}

The governance structure and the implementation of EUSAIR is complex given the broad scope of each of the four thematic areas, the absence of a legally binding framework, and the lack of a "go-to" body that can provide guidance on implementation practicalities and managing the capacity gaps among participating countries. In addition, there are differences in the frameworks for programming, planning, funding, and reporting between EU member and non-EU member states, as well as among EU programming tools and interventions. While the EUSAIR Facility Point and the in-country Facility Point Project Partners can and do provide valuable project and technical support, additional support on a 
strategic level - particularly with respect to minimising or bridging the gaps - is missing. ${ }^{1}$ Implementation relies on the ability of each country to successfully support a variety of needs, including policy and investment coordination across sectors and across borders, with their existing multi-level governance mechanisms. Several challenges have been present from the strategy's inception, such as the "3 No's" as well as fragmentation and misalignment in financial resources and the rules for their use.

The OECD has extensive experience working with South East Europe through its South East Europe programme and the SIGMA programme. Since its inception in 2000, the OECD South East Europe regional programme is dedicated to supporting the Western Balkan economies in designing and implementing policies for robust, inclusive and sustainable growth. OECD policy support in the region combines in-depth analysis, with the formulation of recommendations, the exchange of international good practices, public and private stakeholder dialogue, and capacity-building. By facilitating an evidence-based dialogue, OECD projects in the region also aim to contribute to fostering co-operation among Western Balkan countries. The OECD also supports the efforts of the Western Balkans to move closer to EU and OECD standards. The SIGMA programme is a joint OECD and European Commission initiative, working with partner governments that include Albania, Bosnia and Herzegovina, Montenegro and Serbia. Its aim is to strengthen the foundations for improved public governance and support socio-economic development, working in close collaboration with centres of government, state agencies, independent oversight bodies and parliaments.

The OECD was asked by the European Commission to identify the multi-level governance structures supporting the strategy in each country, in order to gain a better understanding of the challenges and opportunities with respect to potential policy outcomes. The methodology consisted of a background questionnaire sent to countries in Spring 2017, a series of national case studies focused on multi-level governance institutional and administrative structures, arrangements and tools, and individual country visits, as well as desk research.

The discussion in this report focuses on what was reported and observed with respect to the multi-level governance systems supporting EUSAIR implementation in the individual participating countries. It does not undertake a detailed analysis of the activities and accomplishments in each Pillar or by key implementers, or at the broader EUSAIR level. The discussion is fixed in time, reflecting information gathered and multi-level governance practices in place in 2017, with updates through early 2018. In certain instances, the specific governance mechanisms supporting EUSAIR have evolved since then. However, the overall findings remain valid into Q4 2018. It should be noted that the structures in place to support the strategy's implementation can vary from what is in the EUSAIR documents outlining these. Finally, in this study, the concept of "multi-level governance" extends from the European level to the local level and includes cross-sector coordination at each. The analysis identified a series of common, persistent challenges - some of which reinforce each other - that may hinder the full achievement of EUSAIR's objectives, specifically:

- A series of coordination challenges across sectors and levels of government

- Funding challenges

\footnotetext{
${ }^{1}$ The Facility Point(s) and/or Facility Point Project Partners could play such a role, but a clear mandate to do so would be required, and would shift their nature towards that of a secretariat for EUSAIR in each country.
} 
- Limitations in human resource capacity

- Weak links with EU and national strategies

- Limited participation of subnational and non-government stakeholders

These challenges are not insurmountable, but they will require action by actors involved at all levels of EUSAIR governance. This report elaborates on the main elements that form the list of challenges, and concludes with recommendations on how to strengthen the multilevel governance of the strategy.

\section{EUSAIR multi-level governance structures}

Countries participating in EUSAIR organise the multi-level governance system supporting the strategy around their unique institutional settings and administrative organisations. This said, they have generally maintained a structure that aligns with the strategy's own: National Coordinators at the governing board level (political decision-making); Pillar Coordinators $^{2}$ spearheading each thematic pillar; and Thematic Steering Group representatives (TSGs) from the relevant line ministries who are responsible for providing technical expertise and input for each pillar (Figure 1). There are officially two levels of governance for the strategy - National Coordinators on one level and pillars (Pillar Coordinators + TSG members) at the other. In practice, however, there seems to be a slight separation between Pillar Coordinators and national TSGs representatives within individual countries. Pillar Coordinators appear to be fulfilling a critical and intermediate level role vis-à-vis the national-level thematic steering groups and the National Coordinators, taking them out of the technical function attributed to TSGs and putting them into one that is also advisory and strategy/policy oriented.

\footnotetext{
${ }^{2}$ Pillars Coordinators for Pillar 1 are Greece and Montenegro; for Pillar 2 - Connecting the Region are Italy and Serbia; for Pillar 3 are Slovenia and Bosnia and Herzegovina; for Pillar 4 are Croatia and Albania.
} 
Figure 1. EUSAIR National coordination structures and information flows within participating countries

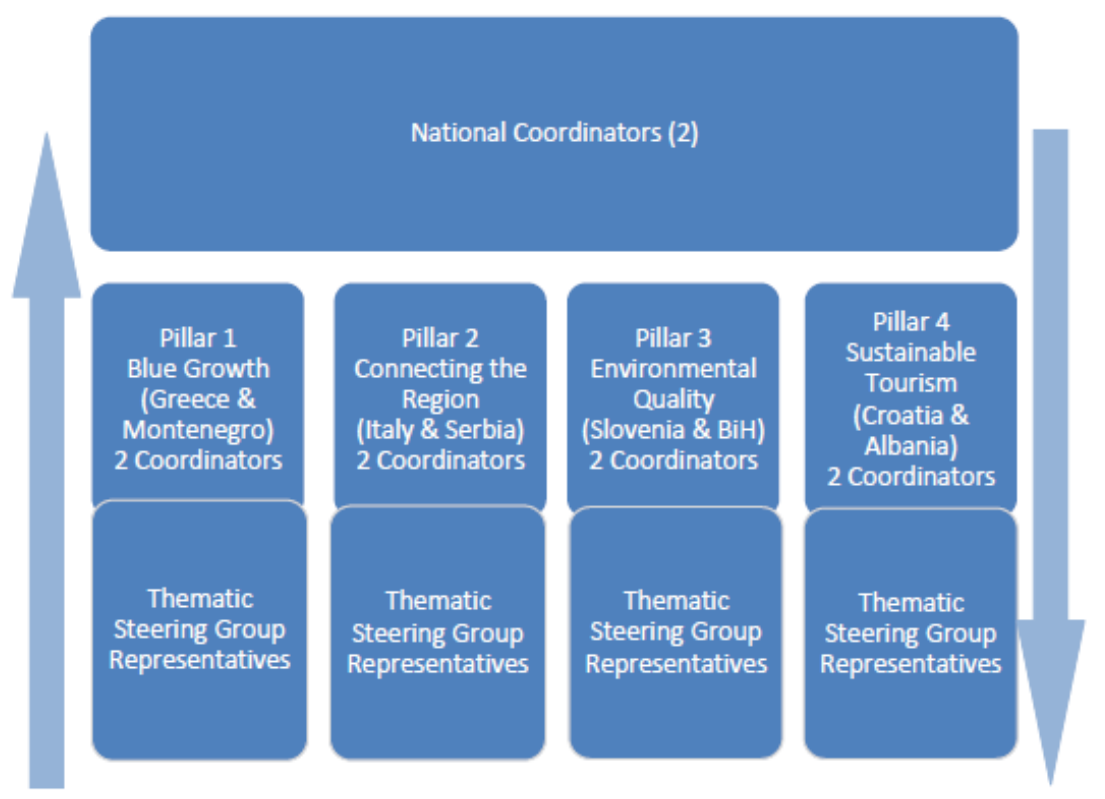

Notes: The numbers are indicative, most countries have two National Coordinators, and one assigned Pillar Coordinator. In the case of Pillar 2, which is divided into two sub-pillars, one for energy and the other for transport, there are two sets of Pillar Coordinators, one set for each theme. The number of national Thematic Steering Group representatives can vary.

Source: OECD Elaboration.

The general approach is logical but also quite compartmentalised, with information flows that more often tend to be vertical - both top-down and bottom-up - than horizontal or diagonal (e.g. from a Pillar 1 Coordinator to a Pillar 4 TSG). This is common in the institutional dynamics of many, if not most, governments. However, horizontal coordination challenges are reported, particularly at the Pillar/TSG level(s), underscoring the need to foster and sustain cross-sector dialogue and cooperation. While the National Coordinators play an important role in disseminating information horizontally and diagonally, more could be done in all countries to promote this at and among the Pillar/TSG levels. Additionally, greater coordination support may be valuable from the European level (e.g. DGs with an interest in advancing the Strategy's different themes).

\section{Key institutional bodies to support EUSAIR}

The strategy's organising document calls for two National Coordinators - one from the Ministry of Foreign Affairs and one from the ministry or body responsible for EU Funds or EU Integration (EUSAIR, 2014). In most countries, the multi-level governance system for EUSAIR reflects this. However, where there is only one coordinator this is due either to a slow or lengthy nomination process and/or to structural changes at the institutional level. For example, the merging of the Ministry of Foreign Affairs and the Ministry for EU Integration in Albania.

EUSAIR's implementation depends on a wide variety of ministries and national-level institutions with varying degrees of involvement (depending on the relevance of a Pillar or topic to national interests) (Annex A). This represents a significant coordination challenge. National coordination mechanisms for EUSAIR vary from country to country and their 
effectiveness can depend on existing national practices as well as internal government capacity to absorb additional responsibilities. For the most part, all countries rely on a variety of arrangements, and in almost all cases there is some form of inter-ministerial interaction (Table 1). Inter-ministerial committees and working groups can be strong mobilising and organising forces. Such bodies could be considered a good practice, particularly with a strategy as thematically broad and complex as EUSAIR. In the case of EUSAIR, such groups have been established at different points in time and their impact on the strategy and its implementation will depend on their maturity, as well as the active participation of the diverse ministries involved. This in turn, may also depend on government stakeholder understanding of the strategy and its value added, and their incentive to participate. In some countries, such as Slovenia with its extensive experience with macro-regional strategies, communicating the value added-of the strategy has not been as challenging as it reportedly is in other countries, particularly non-EU member country participants.

Table 1. Overview of arrangements for EUSAIR implementation across central ministries

By country, as of April 2017

\begin{tabular}{|c|c|c|c|c|c|c|c|c|}
\hline $\begin{array}{c}\text { Arrangement/Instrument } \\
\text { for EUSAIR } \\
\text { Implementation }\end{array}$ & Albania & $\begin{array}{l}\text { Bosnia- } \\
\text { Herzegovina }\end{array}$ & Croatia & Greece & Italy & Montenegro & Serbia & Slovenia \\
\hline $\begin{array}{l}\text { Inter-ministerial } \\
\text { Committee }\end{array}$ & & & $x$ & $x$ & $x$ & & $x$ & $x$ \\
\hline $\begin{array}{l}\text { Regular inter-ministerial } \\
\text { meetings }\end{array}$ & $x$ & & $x$ & $x$ & & $x$ & & $x$ \\
\hline $\begin{array}{l}\text { Joint inter-ministerial } \\
\text { strategy agreement }\end{array}$ & & & & $x$ & & & & $x$ \\
\hline $\begin{array}{l}\text { Governance } \\
\text { arrangements to manage } \\
\text { EUSAIR-relevant funding }\end{array}$ & & $x$ & & $x$ & & & $x$ & $x$ \\
\hline \multicolumn{9}{|l|}{$\begin{array}{l}\text { Signed formal inter- } \\
\text { ministerial agreements }\end{array}$} \\
\hline $\begin{array}{l}\text { Cross-sector coordination } \\
\text { of the subnational level }\end{array}$ & & & & $x$ & & $x$ & $x$ & $x$ \\
\hline \multicolumn{9}{|l|}{ Other: } \\
\hline Ad-hoc meetings & $x$ & & & & & & & \\
\hline $\begin{array}{l}\text { Government decisions; } \\
\text { Parliamentary decisions }\end{array}$ & & & & & & & & $x$ \\
\hline
\end{tabular}

Note: While Montenegro does not have an inter-ministerial committee for EUSAIR, the National Council for Sustainable Development, Climate Change and Integrated Coastal Zone Management serves as an advisory body to the Government of Montenegro on sustainable development and environmental matters, and thus indirectly on matters concerning the Strategy. The Council, chaired by the President of Montenegro, is comprised of national, subnational, private sector and civil society stakeholders, and has four expert working groups for dialogue and coordination on sustainable development issues.

Source: Country responses to OECD questionnaire circulated in April 2017.

Coordination mechanisms applied to EUSAIR across levels of government tend to combine the informal (i.e. personal relationships, email, telephone exchange, etc.) with the more formal. These can include ad hoc meetings, (e.g. Albania), regular meetings (e.g. Montenegro, Serbia and Slovenia), formal committees (e.g. Croatia, Italy, Serbia, and Slovenia), or sector working groups (e.g. Bosnia-Herzegovina) (Table 2). Most countries rely on more than one mechanism and some, such as Greece, also use networks associated with EU funded programmes. 
Table 2. Overview of arrangements for EUSAIR implementation across levels of government

By country, as of April 2017

\begin{tabular}{|c|c|c|c|c|c|c|c|c|}
\hline $\begin{array}{l}\text { Arrangement/Instrument } \\
\text { for EUSAIR } \\
\text { Implementation }\end{array}$ & Albania & $\begin{array}{l}\text { Bosnia- } \\
\text { Herzegovina }\end{array}$ & Croatia & Greece & Italy & Montenegro & Serbia & Slovenia \\
\hline Regular meetings & & & & & & $x$ & $\mathrm{X}$ & $x$ \\
\hline Ad hoc meetings & $x$ & & $x$ & $x$ & & $x$ & $x$ & $x$ \\
\hline Formal committee & & & $x$ & & $x$ & & $x$ & $x$ \\
\hline Joint strategy agreement & & & & & & & & $x$ \\
\hline \multicolumn{9}{|l|}{$\begin{array}{l}\text { Signed formal agreement } \\
\text { between ministries and/or } \\
\text { stakeholders }\end{array}$} \\
\hline Joint platform & & & & & & & & $x$ \\
\hline $\begin{array}{l}\text { Strategic development } \\
\text { document }\end{array}$ & & & & & & & & $x$ \\
\hline Co-financing tools & & & & $x$ & & & & $x$ \\
\hline \multicolumn{9}{|l|}{ Others } \\
\hline $\begin{array}{l}\text { National Strategy for } \\
\text { Development and } \\
\text { Integration }\end{array}$ & $x$ & & & & & & & \\
\hline Sector working groups & & $x$ & & & & & & \\
\hline $\begin{array}{l}\text { Special Network of local } \\
\text { points per MA of EU } \\
\text { Funded Programmes }\end{array}$ & & & & $x$ & & & & \\
\hline $\begin{array}{l}\text { Government decisions, } \\
\text { Parliament decisions, } \\
\text { Fora, Events, } \\
\text { Conferences }\end{array}$ & & & & & & & & $x$ \\
\hline
\end{tabular}

Notes: The table does not consider the National Contact Points that are attached to National Coordinator offices for EUSAIR or other EU Programmes (except for Italy where the Facility Point is attached to the Marche Region).

The Indicative Strategy Paper for Bosnia-Herzegovina defined the support priorities covered by the Instrument for Pre-Accession Assistance (IPA II) for 2014-2017 in a selected number of sectors, which expanded to include transport in 2017 and environment in 2018. It remains unclear when energy and tourism will be included. This offers one explanation behind Bosnia-Herzegovina's limited number of implementation arrangements. In Slovenia, the Joint Strategy Agreement is the Single Government Information/Report. Source: Country responses to OECD questionnaire circulated in April 2017.

\section{A need for clearer and more harmonized attribution of responsibilities}

There is a delineation between the National Coordinators, Pillar Coordinators and TSGs at the strategy and national levels, particularly as these representatives fill different functions within the strategy and their own governments. However there is some doubt if the attribution of responsibilities is clear- a point echoed particularly among TSGs in a capacity building event led by the EUSAIR Facility Point in March 2018 (EUSAIR Facility Point, 2018). For example, which group or level can set the overarching policy approach to meeting Pillar objectives? Is it, or should it be, the Pillar Coordinators in conjunction with the National Coordinators? Is it the National Coordinators with the relevant high-level ministerial representatives (as representative of the government)? Or the inter-ministerial committees or working groups where they exist? Who is responsible for mobilising the relevant sector ministries and civil servants who can help support meeting objectives, as well as regional or local representatives? Should TSGs play a role in setting policy? Regardless of what is written in the document(s) establishing EUSAIR that outline its governance frameworks, in practice the evolution is more nuanced. This is reflected in the 
national practices and the actual implementation of the strategy's governance structure. It appears that the role and mission of TSGs has been interpreted differently by the participating countries, resulting in different working methodologies, different levels of assistance and feedback received by national administrations, different levels of input provided, and different levels of accountability. Very clearly establishing the roles and expectations of each category of participant, and ensuring consistency across countries in this respect would be important and facilitate dialogue, collaboration, and decision-making.

One of the reported challenges faced, particularly by TSGs, but in some cases also by Pillar Coordinators, is an unclear mandate from their national administrations, be it with respect to level of participation, degree of input, or decision-making capacity. Altogether, this can reflect an insufficient level of empowerment to contribute to dialogue, agree to proposals made, and ensure implementation in the home country, thereby affecting the strategy's overall governance as well as participation and implementation at the country level. It also affects ownership within the strategy itself.

In some instances, there may be gaps in TSG expertise - either with the theme at hand or with understanding EU funding procedures. This could be attributed to staffing constraints where countries do their best to fulfill human resource requirements within their administrative and resource limitations. It might also reflect a need for a general technical or professional profile (e.g. type of experience) for TSG representatives, although this is entirely up to the country and its approach to human resource management.

General national governance practices also affect the EUSAIR in-country governance structures and practices. Expected and unexpected changes in the organisation of governmental structures (e.g. ministries) occurring close to or in the aftermath of elections often result in changing membership within the nationally established inter-ministerial coordinating bodies that support the implementation of the EUSAIR, as well as at the Pillar Coordinator/TSG levels, weakening overall capacity for action. At the technical/implementation level, TSG activity can be limited as a result of delays in designating a TSG representative (often due to administrative requirements, and particularly in non-EU member countries), insufficient continuity among members (TSG representatives change due to internal government or ministerial changes), and poor attendance at meetings (often due to limited resources) ${ }^{3}$. This can result in TSGs with limited information or knowledge of the group's activities and previous discussions, making it more difficult for them to engage and contribute to decision making. Overall, this situation affects the efficiency and effectiveness of EUSAIR governance structures and the continuity of action undertaken by individuals, delaying relevant decisions for the strategy and its implementation. In order to address this effectively, on many occasions countries have put forth the need for stronger political support at the EU level, including by the DGs, as well as at the national, and often national-political, level.

Enhancing the harmony in the approach to EUSAIR governance structures taken by participating countries could be beneficial. This is particularly the case with respect to TSGs, in order to ensure each representative has the same level of responsibility for dialogue, decision making and implementation, both within the structure of the group and in their national administrations. Clarity as to the types of decisions taken at higher levels may also be helpful to ensure stronger/more effective decision-making processes and

\footnotetext{
${ }^{3}$ This specific aspect of limited resources is gradually being overcome as in-country Facility Points are established and becoming operational in each country, but it remains to be seen if the issue can be fully addressed.
} 
ownership throughout the multi-level governance framework. To enhance the ability of the distinct levels of the EUSAIR national coordination structure to adopt and fund EUSAIR actions, it is important to ensure that all national representatives are familiar with national priorities (especially in the sectors relevant to EUSAIR), EUSAIR priorities within and across pillars (as well as how these priorities intersect), and the priorities for action decided upon within the context of the strategy.

\section{Tools to support governance frameworks and strategy implementation in participating countries}

A strategy as far-reaching and elaborate as EUSAIR requires institutional support at all levels: European, national, and subnational. At different speeds and with different levels of success the national and European levels have been working to design and implement tools to support resource shortfalls and build communication capacity.

With respect to resource support, the EUSAIR Facility Point (Box 2) and Facility Point Plus projects are highly relevant, and have been welcome by participating countries. However, some care will need to be taken to clarify the exact responsibilities and tasks of the Facility Point Project Partners, newly established within countries, so that they themselves do not get overwhelmed and fall short of resource capacity. Thus far, under the guidance of the Slovenian Facility Point Lead Partner, the Facility Point Project Partners that are established and becoming progressively operational in each country are providing logistical, operational and administrative support, particularly for meetings. If they are also expected to function as a secretariat for EUSAIR implementation, which could be helpful, this should be clarified in each country, and thought should be given to harmonising their activity throughout the network, at least in broad terms. While the project is a fundamental tool for each country and the strategy, there is some concern that too many expectations have been placed on it, particularly as a stand-in for resources that may need to be more closely associated with implementation partners (e.g. line ministries) throughout the EUSAIR governance structure. In addition, care may need to be taken that the Facility Point Project Partners are not considered substitutes for the human and administrative resources needed among national and regional administrations to fulfil their tasks as EUSAIR key implementers. 


\section{Box 2. The EUSAIR Facility Point Project}

The EUSAIR Facility Point project, funded through the ADRION programme, was introduced to support EUSAIR governance structures and build implementation capacity for the strategy. It is structured around a series of work packages. One of these is designed to provide essential administrative and operational support to the Governing Board, National Coordinators and Thematic Steering Groups, including inter-pillar coordination and coordination with other macro-regional strategies when appropriate (Work Package T.1). Additional work packages include facilitating strategic project development and promoting financial dialogue (Work Package T.2), building monitoring and evaluation capacity to contribute to evidence and knowledge bases (Work Package T.3), and supporting cross-sector, multi-level communication and dialogue through an online stakeholder platform (Work Package T.4). The project involves all eight countries (project partners) and is led by Slovenia (the lead partner).

The EUSAIR Facility Point project's overarching tools to support the strategy's governance cannot carry the weight themselves. They need to be complemented by internal stakeholder commitment and ability to move from promoting national to macro-regional interests. It also calls on capacity to promote dialogue and exchange, for example, to effectively influence peers within home administrations with respect to the strategy's value and contribution, and to communicate about the opportunities the strategy offers, internally within government and among external stakeholders. They also need high-level support and guidance from the European level.

The Stakeholders Platform is eagerly awaited by participating countries. It is intended for government and non-government stakeholders as an online tool to support communication and information flows. It would be a "go-to" website for the strategy helping identify project and funding opportunities (including possible calls) as well as providing information on projects that are underway. Unfortunately, the launch of the platform has been delayed and therefore is not able to catch most - if any - of the calls in the 2014-2020 programme period, which is a handicap for the strategy. It is widely recognised that communication surrounding the strategy is a shortcoming, and requires improvement (European Parliament, 2018; OECD interviews; OECD case studies).

\section{Coordination challenges need to be overcome}

Successful national, trans-national and multi-level coordination is a key factor in achieving EUSAIR's ambitions. This is especially true since the " 3 No's" do not permit establishing formal strategy-specific institutional structures, founded on EU regulations, that could ensure such coordination; and particularly important given the fragmentation and diversity in terms of resources, tools and capacities of each country. It is also fundamental to implementing the EUSAIR Action Plan which requires the mobilisation and alignment and hence coordination - of all available EU, international, national and private support.

There is a need for greater capacity and incentive for cross-sector coordination, as well as better vertical and horizontal coordination mechanisms. On the one hand, taking a more holistic perspective may be necessary - in other words, ensuring that countries agree with approaches to the common goal of overcoming the socio-economic disparities and imbalances in the region as well as in institutional and administrative capacities. On the 
other hand, stronger tools or mechanisms to promote such coordination are critical, especially in the short term.

\section{Cross-sector coordination}

Cross-sector coordination is perhaps the most important success factor for EUSAIR. Interministerial working groups can and do help with this, particularly at a high-level. The greater challenge, however, is at the Pillar/TSG levels, where there is more limited crosssector cooperation and coordination. This may be due to national governance cultures that are top-down and siloed. In such cases, working in an integrated or cross-sector manner is out of the ordinary and requires practice. It can also be due to a lack of incentive from the top, or a lack of full understanding regarding how the strategy can support national and individual sector objectives. Cross-sector coordination is almost always difficult, and can be made easier when directly supported from above. It appears that in many participating countries a clearer perception of need for such coordination in support of EUSAIR is necessary at the national political level in order to begin overcoming coordination and implementation challenges. The strategy's own structure may also be compounding the problem, as the Pillars themselves are highly sector-driven. This makes it feasible to address all four pillars individually, without working in a cross-pillar fashion. While this is not ideal and is antithetical to the spirit of the strategy, it is nonetheless possible. Regardless of the reason, all countries report limited interaction between Pillars and among distinct TSGs. This said, all countries also report good communication flows within the Pillars and within the TSGs.

There have been initiatives among EUSAIR key implementers to address this issue. For example, Pillar 3 developed an extensive matrix to identify where its priorities and those of the other three Pillars intersected, also highlighting the degree to which the priorities could match - from a perfect match, to incompatible, to no match. For example, the matrix identified Pillar 3 priorities with respect to pollution of the sea to match well with a significant number of Pillar 1 priorities, particularly with respect to maritime and marine governance and services, while highlighting that these same priorities may be in conflict with a number of priorities in Pillar 2. Slovenia's green-blue corridor initiative not only has a positive incidence on Pillar 3, but also is relevant for Pillar 2 and Pillar 4. By connecting protected areas long its coastline, it has improved the sustainability of its wetlands, and built a more tourist-friendly environment. It has also contributed to improving the territory in which the port of Koper operates by naturally cooling the industrial area, by helping prevent floods, and more broadly by improving the quality of life for Kopor residents (EUSAIR, 2018b).

The difficulties in cross-sector coordination may be affecting the ability for countries to fully consider the strategy's horizontal aspects (capacity building, research and innovation, and SMEs) as well as its horizontal principles (climate change and risk management). Despite dedicated sessions at the annual EUSAIR Forum, thus far, these cross-cutting themes do not appear to have received a significant amount of ongoing attention, and there is no mechanism within the national coordination structures to ensure they are supported. By contrast, in the European Union Strategy for the Danube Region (EUSDR), institutional capacity and cooperation is a priority area. These horizontal or cross-cutting themes could offer a valuable platform or framework for solving common strategic problems and could help build greater cross-sector coordination.

The issue of cross-sector coordination also arises in relation to initiatives of national interest that need high-level political and technical support. The challenge here, however, 
is how to maintain a macro-regional perspective rather than a national, regional or sectoral one when called to consider projects. In Pillar 2 (Connecting the Region) for example, all participating countries in the TSG have developed a strategic approach to project selection and identified two strategic projects per country to propose for future financing, mainly based on national gap analysis. This is also true for non-EU member countries that have developed Single Project Pipelines for infrastructural projects in the framework of IPA II ${ }^{4}$. Outside of EUSAIR, Sweden offers a good example of cross-sector and multi-stakeholder coordination for the European Union Strategy for the Baltic Sea Region (EUSBSR), which also highlights the importance of high-level political support (Box 3).

\section{Box 3. Cross-sector and multi-stakeholder coordination in Sweden}

Sweden established a national coordination unit within the Prime Minister's Office to coordinate the Swedish contribution to the European Union Strategy for the Baltic Sea Region (EUSBSR), offering a good example of effective cross-sector and multistakeholder coordination. All 44 concerned agencies and other implementation authorities have been given specific tasks relating to Sweden's contribution to the macroregional strategy and are required to report on its progress and implementation once a year. The Swedish Partnership Agreement emphasizes the role of the Swedish Agency for Economic and Regional Growth (Tillväxtverket) for EUSBSR coordination and monitoring. It is also responsible for spreading knowledge and information about the strategy and explaining how macro-regional strategies can support national priorities. In addition, Tillväxtverket has responsibility for issues pertaining to the multiple ESI Funds and serves as the Managing Authority for mainstream regional programmes. This approach allows Tillväxtverket to ensure efficient cooperation between the different levels of policymaking in Sweden, EUSBSR and the relevant authorities managing ESI Funds.

Source: European Commission, European Union Strategy for the Baltic Sea Region - Interim Report on the implementation of the EU Strategy for the Baltic Sea Region, Annex III Organisation of Work, October 2010; https://tillvaxtverket.se/english.html; OECD (2018, unpublished), "OECD Seminar Proceedings: Strengthening National Coordination Mechanisms for EUSAIR”, OECD Seminar, Podgorica, Montenegro.

\section{Vertical coordination}

Vertical coordination runs from the European level to the local level. It is a common, highlevel challenge in multi-lateral strategies, and in the case of EUSAIR it is a challenge for several reasons. First, while in Greece and Italy regions exist as constitutionally recognised entities with a defined set of responsibilities to meet, in other countries this is not necessarily the case, and in some instances regions are statistical units rather than political or administrative bodies. In the latter two cases, the national government could conceivably coordinate with intermediate and local authorities. However, the argument can be made

\footnotetext{
${ }^{4}$ The Single Project pipeline is a tool for monitoring national infrastructure priority projects in IPA Countries, especially in the framework of Negotiating Chapter 22 for Regional Development. The Serbian model was developed by the former Serbian EU Integration Office (SEIO), now MEI. It was created for a variety of reasons, including: to avoid an ad hoc approach to planning preparation and implementation of infrastructure projects; to meet the need for project prioritisation (developed set of criteria reflecting EU and national strategy and policy goals focusing on economic development); to enable systematic and timely planning of resources; to provide a reliable basis for defining proper sequencing of the actions; and to help link investments planning and programme budgeting.
} 
that there is still little to coordinate as subnational governments, particularly local authorities, are not fully engaged in the strategy, and that this will change with time. Second, and more importantly, among countries where the active involvement of subnational governments in policy design and implementation is limited, the National Coordinators and relevant coordination structures have few mechanisms for efficient engagement, particularly with respect to local authorities. The fact that there is no specific funding associated with the strategy and that the funding mechanisms that do exist can be complicated, are critical factors behind limited subnational, and especially, local engagement.

The Italian approach, with its central-regional coordination mechanism ${ }^{5}$ has been cited as a good example of vertical coordination. The mechanism is institutionalized and supported by Cabina di Regia at the Presidency of the Council of Ministers. It is a good practice, but it must be remembered that Italy has a long tradition of vertical coordination, one that is rooted in the Italian Constitution. Thus, the coordination mechanisms between the Italian TSG members from the national and regional levels, as well as between the central and regional administrations, are founded on specific arrangements first agreed upon among the regions themselves. This relationship is reinforced in some regions by their role in specific initiatives, for example the Marche region's responsibility for the Facility Point Project in Italy. Despite required involvement, this does not guarantee high levels of commitment, which can vary among national and regional TSG representatives, often depending on the relevance and available national-level funding for sector investment strategies.

Another obstacle to vertical coordination is a perception that EUSAIR is a national-level endeavour and responsibility. Such a perception appears to be true throughout the multilevel governance chain, from the different, relevant DGs to national and subnational levels of government. This highlights a coordination and dialogue gap between those who are called to design and implement policies at the European, strategy, and national levels, and the subnational or local levels that are called to implement policies through projects on the ground.

\section{Horizontal coordination}

Horizontal coordination also needs to be considered at several levels - European, crossborder, national and eventually subnational levels - as it represents a serious challenge that needs prompt intervention.

With respect to EU mechanisms, there is generally insufficient coordination between EUSAIR and EU-funded programmes. The coordination and cooperation between the Managing Authorities and relevant OPs, and EUSAIR key implementers at the national level can be irregular despite being critical for transforming programme alignment into concrete funding opportunities. A strategy like the BLUEMED Initiative financed by Horizon 2020 may be a good practice example for ensuring sustainability and for transnational and cross-border collaboration (and funding) - both at the technical and political levels - particularly for Pillar 1 maritime governance projects. It offers a shared strategic framework for working towards a healthy, productive and resilient Mediterranean Sea, and stresses the importance of joint and aligned research and innovation strategies, programmes and activities in the Mediterranean Sea Basin. It is based on its own vision

\footnotetext{
${ }^{5}$ The coordination occurs through the Cabina di Regia, the regional working group and the process of sharing relevant decisions through the State-Region Conference.
} 
document (the Strategic Research and Innovation Agenda - SRIA), which was presented by the proposing countries at the end of 2014 (European Commission, 2015).

At national levels, the national (and, where applicable, regional) inter-ministerial coordination mechanisms (e.g. committees, working groups, ad hoc meetings) established by the various partners may be able to obtain high-level commitment to the concept of EUSAIR. In general, however, there seems to be difficulty translating this down to the implementation level where there greater difficulty is reported in encouraging relevant ministries to engage, for example by drafting or revising sector policy and planning documents to incorporate EUSAIR objectives, or through specific projects. When it does occur, it is not systematic, rendering the presence and visibility of macro-regional priorities within ministerial action weak.

\section{Dialogue processes and networking}

Another coordination challenge facing the multi-level governance of EUSAIR are the difficulties that participating countries encounter in dialogue processes and the positions represented by officers of diverse European-level directorates or delegations. These processes can be uneven, with European institutions adopting unclear or differing positions regarding EUSAIR and/or expressing different levels of awareness or support for the strategy. This is then reflected further down the multi-level governance chain. A gap has been noted between political commitment emphasised by ministers and the ability of national administrations to follow up on this commitment (European Commission, 2016). This can be attributed to human resource and funding challenges. However, it can also be due, at least in part, to a need for clearer dialogue processes and presence of high-level representatives of the European level (European Commission, 2016). The role of the European level in the success of this strategy cannot be underscored strongly enough. Clear guidance, and perhaps more importantly, active political and technical engagement by the relevant European actors carry significant weight and can go a long way to encourage the political and technical levels in participating countries (European Parliament, 2018). This is true for all participants, but may be particularly so for non-member countries. While the active support of the European level is important for all macro-regions, it is especially so in the case of EUSAIR given the region's complexity, the difference in capacities among participating countries, and the fact that the strategy is still relatively young. For the most part, the other three macro-regions are populated by countries that have more EU experience and greater resource capacity.

The need for dialogue and networking processes has several dimensions. The first is an EU and international dimension; the second is within and among national coordinating structures; and the final one is across macro-regional strategies. Each country organises dialogue meetings among the Managing Authorities of mainstream programmes (e.g. Operational Programmes and European Territorial Cooperation programmes) and EUSAIR. Strengthening the conversation at the TSG level, or in some cases extending it to this level, could help improve the regularity of information flows between Pillar reference officials and the authorities managing Operational Programmes (OPs). This is important if a closer or stronger link is to be established between the OPs and EUSAIR for project and funding opportunities. To this end, the example of the established EU Strategy for the Baltic Sea Region (EUSBSR) network (Box 3) could be of value. In addition, a network of Managing Authorities in the EUSAIR area could enhance transnational cooperation in implementing EUSAIR goals through recourse to transnational components in ESI funds (for example EU Regulation 1303/2013, Article 70.2), thereby promoting a more strategic alignment of funding (Box 4). 


\section{Box 4. The Managing Authorities Network in the Baltic Sea Region}

In the framework of the EU Strategy for the Baltic Sea Region (EUSBSR), a pilot ERDF Managing Authorities Network was set up in 2016. It explores opportunities for transnational collaboration (for ERDF funded projects) via the Common Provision Regulation of Article 70.2 [and/or Article 96.3(d)]. Its aim is to facilitate support from regional, country-specific and multi-country operational programmes for EUSBSR implementation. The network's initial focus was on projects concerning Innovation and Smart Specialisation Strategies. The Managing Authorities (MA) Network is based upon the no Lead Partner Principle and upon the need for an activities coordinator to ensure that all activities are interlinked and carried out according to plan. At the same time, the coordinator acts as a contact point for project stakeholders and is responsible for internal and joint-external communication of project activities.

Thus far, the MA Network has garnered significant local and regional interest as means to exploit smart specialisation strategies through transnational collaboration. Managing Authorities for ERDF programmes reportedly are welcoming transnational collaboration, bringing new energy to macro-regional collaboration. Similar networks have emerged for the European Social Fund (ESF) and the European Agricultural Fund for Rural Development (EAFRD) within the macro-region, signalling a will to cooperate across regions and programmes.

The MA Network plans to launch an initiative focused on digitalisation, with project seed money provided by the Swedish Institute. Project proposals will be presented in June 2018 at the $9^{\text {th }}$ Annual EUSBSR Forum in Estonia, and possibly launched through a coordinated call.

Source: European Commission (2016), Staff Working Document accompanying the document on the implementation of EU macro-regional strategies "Report from the Commission to the European Parliament, the Council, the European Economic and Social Committee and the Committee of Regions" - SWD (2016) 443 final, 16/12/2016. http://s3platform.jrc.ec.europa.eu/s3-in-baltic-sea-region; Forsling N. (2017), ERDF Managing Authority Network - PA/Innovation, Macro regional strategies - What's in it for Cohesion Policy; presentation, EUSBSR 8th Annual Forum in Berlin, 13/6/2017; http://www.painnovation.eu/news/erdf-ma-network-welcoming-new-topics-for-collaboration/; $\quad$ EUSBSR (2017a), "Macro-regional strategies - what's in it for Cohesion Policy?, presentation", EU Strategy for the Baltic Sea Region, 8th Annual Forum in Berlin, 13/6/2017, https://www.balticsea-region-strategy.eu/8th-annualforum/programme/16-8th-annual-forum/seminar-information/590847-macro-regional-strategies-and-theirlinks-with-cohesion-policy; Svenska ESF-rådet (Swedish ESF Council) (n/d), "Baltic Sea Network", official website, https://www.esf.se/en/Sidhuvud/The-swedish-ESF-council/Baltic-Sea-Network/; EUSBSR (2017b), "BSN-EAFRD network", presentation, available at https://www.balticsea-regionstrategy.eu/attachments/article/590918/BSN-EAFRD\%20presentation\%202017.pdf.

Stronger ties through dialogue and networking offer wider opportunity for exchanging experiences, understanding the unique needs and challenges of specific projects, sharing common practices, and identifying how to make policies and programmes more effective. It can contribute to building cross-sector dialogue and coordination - connecting line ministries and institutions and softening strongly sector-driven approaches. At the same time, in order to be effective, this type of dialogue needs support from the relevant European-level institutions (including those that work on transnational cooperation), as well as national bodies. Based on the eight case studies, such dialogue does not appear to be occurring on a formalised, consistent and regular basis within the macro-region. 
Experience from the Baltic Sea Region, particularly the cases of Poland and Sweden highlight the value and extent of dialogue and networking bodies (Box 5).

\section{Box 5. National level coordination and dialogue bodies in the Baltic Sea Region}

\section{The EUSBSR Working Group in Poland}

In 2011, Poland's Ministry of Foreign Affairs set-up a national Working Group in order to support the National Coordinator implement the European Union Strategy for the Baltic Sea Region (EUSBSR). Formally, it counts with high-level representation (minister/deputy minister rank), and initially it functioned within a formal framework of nominated delegates, etc. With time, however, it became apparent that the Working Group would be more useful if all interested parties could participate (this has also helped better manage challenges associated with staff rotation). Today, the Working Group is comprised of representatives from different ministries, Managing Authorities (for national and regional Operational Programmes), local governments/administrations, Polish Policy Area coordinators and flagship leaders/partners for EUSBSR, as well as external stakeholders, such as regional organisations, academia, institutes, local foundations, NGOs, etc.

Initially, the Working Group served as a forum for explaining what EUSBSR was about, and communicating its potential to internal stakeholders. Over time, it has focused on inviting thematically-relevant potential stakeholders from all over the country in order to expand the engagement of Polish beneficiaries with the strategy. The Working Group meets two to three times per year, and participants are briefed on recent developments so they can follow important trends and activities (e.g. Action Plan revisions, new funding opportunities, Annual Forum preparations, etc.). The Working Group's broad participant base has helped Poland develop a national database of contacts (national and subnational) that contributes to coordination and participation efforts, particularly with respect to disseminating information regarding EUSBSR developments and new funding opportunities. Thanks to a few specific practices, the Working Group has also helped build a sense of ownership for the strategy. For example, participating stakeholders are asked to identify topics they feel are important so that these may be incorporated into the agenda, and they are also requested to contribute to the National Coordinator's annual report, which is then submitted to the Committee for European Affairs.

\section{Taking a network approach to coordination and dialogue for EUSBSR in Sweden}

Sweden's Agency for Economic and Regional Growth (Tillväxtverket) is responsible for coordinating the county's 44 agencies participating in EUSBSR. To do so it relies on a number of mechanisms. These range from ensuring that the participating agencies have very clear assignments to contribute to the strategy, coupled with clearly articulated and specific tasks, to incorporating EUSBSR into the national strategy for sustainable regional growth, to hosting agency network meetings two to three times per year. Representatives from all 44 agencies are invited to the meetings, together with the National Coordinator, relevant ministries and other stakeholders from the national and regional levels. Participants meet and discuss different topics related to the strategy and its implementation. They receive updates from the National Coordinator regarding decisions and outcomes from EUSBSR high-level group meetings, as well as updates on EU priorities and cohesion policy. In addition, meetings may also include invited speakers who share practices and insights. For example, representatives from different EU funds may come to speak about financing options, and a stakeholder may be asked to share their experience in identifying 
financing opportunities. Feedback indicates that the meetings are highly appreciated by all actors, and serve as an important coordination tool. The clarity in roles, the active dialogue between Swedish macro-regional strategy representatives and those from mainstream EU programming, and the responsibility for clear communication all contribute to overcoming challenges associated with macro-regional strategies more generally, including financing obstacles and difficulty explaining value added.

Source: Panel discussions, OECD EUSAIR Seminar "Strengthening National Coordination Mechanisms for EUSAIR", 2 October, 2018, Podgorica, Montenegro.

Dialogue and networks among and across the various sets of actors in the EUSAIR national coordination structures is important for exchanging ideas, establishing priorities, and speaking with one voice at EUSAIR meetings with partnering countries. While such meetings do occur, generally in preparation for larger events, they seem more likely to happen within a Pillar rather than across Pillars. A more regular (possibly bi-annual) meeting of all national actors involved in EUSAIR could be valuable not only for ensuring coherence with respect to activities within and across pillars, but also to start building internal networks and dialogue within the country.

Networking with other countries and representatives from other macro-regional strategies can offer ample opportunity for discussion and learning, while also contributing to capacity building. This may be especially true for countries only involved in EUSAIR. Although immediate benefits may be limited, long run effects may be significant. These can include greater visibility and awareness of the strategy, a contribution to project capitalisation and above all to project development (as in EUSBSR), support joint calls and joint implementation of projects as well as targeted calls, identify possibilities of co-funding for cross-border efforts, etc.

\section{Strengthening dialogue and communication with non-government stakeholders}

The matter of overall communication with respect to the strategy is recognised as crucial. EUSAIR has had low visibility in real terms, within governments - particularly among experts and those working with regional development and cohesion policies at the national and subnational levels - as well as among non-government stakeholders. The European Parliament stressed the importance of transparency in adopting, monitoring and evaluating the strategy, as well as of openness and inclusiveness towards civil society and all relevant stakeholders (European Parliament, 2015a). At the same time, it emphasised the essential role of communication and awareness-raising across all pillars for the participation of stakeholders in the decision-making process and for building public support. It also calls for member states to ensure adequate visibility of EUSAIR goals at the national, regional and local levels. Despite this, however, confusion remains in distinguishing between macro-regional strategies and European Territorial Cooperation (ETC) programmes. This underscores the need for significant and clear communication - including in the language used to describe the strategy - and solidly establishing EUSAIR as a strategic framework for the implementation of policies at a national and international level rather than as a tool or reference framework for ETC.

Participating countries have difficulty explaining EUSAIR objectives, value added and priorities to interested parties. The lack of funds or funded projects that stakeholders can easily identify with EUSAIR compounds the problem. It is difficult to call attention to projects under the aegis of EUSAIR as these can often be considered "soft-measures". They require as much work as "hard measures" but quite often the outputs and outcomes are less 
visible. The Stakeholders Platform represents an important tool to address this. However, it cannot promote the strategy on its own - be it to national or subnational officials or nongovernment stakeholders. Governments will need to complement it with internal initiatives, and here Greece's focal network may provide a good example (Box 6). Slovenia's practice of presenting an annual report on the country's participation in EUSAIR to Parliament for public hearing can also be an effective way to highlight the strategy's significance, increase its visibility across government, and build support. The Mediterranean Coast and MacroRegional Strategy Week that Slovenia sponsors is another effective mechanism (described further in the report). A EUSAIR "information day" for public officials could be useful. In addition, single information portals on EUSAIR in each country would be helpful, particularly if they ensure that data and information is in one place, as currently information is often spread across government websites, adding to the fragmentation challenge. While the Stakeholders Platform can contribute to this effort, a national portal may be just as important (it could redirect to the Stakeholder Platform). Building awareness through public information campaigns with the media, etc., may also be advantageous. While such activities could enhance the visibility of EUSAIR, they could also enhance accountability and build ownership.

\section{Box 6. The Greek Focal Network}

Greece's focal network supports the implementation of EUSAIR within the context of each Operational Programme and raises awareness for the strategy and its implementation. The continuous flow of information on EUSAIR by the National Coordination Authority enables focal network nodes to play a significant role in communicating the strategy, informing potential stakeholders and providing the guidance for elaborating ideas that can then be transformed into projects. At the same time, it also supports cross-sector coordination. Such nodes could represent a viable solution as contact point/person relevant to TSG members from each Operational Programme.

The focal network is currently represented by an officer of the relevant Managing Authority responsible for monitoring EUSAIR developments and providing information to potential stakeholders who express their interest in the strategy. The focal network officer is constantly in touch with the National Coordination Authority, regularly receiving information on the strategy, its governance (e.g. Governing Board meetings, inter-ministerial committee meetings, etc.), and implementation. Looking ahead, focal points may play an increasingly important role in disseminating and communicating on ESIF Programmes and the potential of EUSAIR.

To support its communication regarding the importance and value-added of macro-regional strategies, and specifically EUSBSR, Sweden has developed a brochure entitled The Baltic Sea Region Strategy for Beginners targeting all interested stakeholders, be they national or local governments, the private sector, civil society, or citizens. The brochure uses everyday language to clearly explain why the strategy is necessary, what it aims to accomplish, the advantages of participation, what engagement can offer, and how to get involved (Tillväxtverket, 2016). In addition, Tillväxtverket organises education seminars on the macro-regional strategy for management and project officers working with mainstream programmes. Agency representatives are also invited to other relevant and interested organisations to educate them on EUSBSR. 


\section{Monitoring and evaluation processes}

Monitoring and evaluation processes can support greater horizontal and vertical coordination by offering insight into performance - i.e. what is or is not working with respect to a strategy, policy or programme - and the effectiveness of spending. In the case of EUSAIR, monitoring and evaluation mechanisms are being developed for the strategy as a whole. While these will be highly beneficial, they should be complemented by such systems at the country level.

To establish an overall monitoring and evaluation system, and then complement this with individual national systems, it would be helpful to identify a common set of limited quantitative and qualitative indicators that can be used for measurement, qualitative assessment and comparison. Currently, the strategy's action plan offers examples of result indicators and indicative targets, but no list of commonly agreed upon indicators (output and outcome) to which all countries can contribute data. Nor is there a baseline from which to measure or assess progress toward common targets. Developing a homogenous system to monitor and assess results, both those associated with the strategy's overall impact as well as the projects emanating from it, would be valuable. It is expected that the work being led by Greece ${ }^{6}$ in this area will be in place and operational during the first quarter of $2018^{7}$. The monitoring procedures being established for each Pillar could represent a platform upon which to build monitoring and evaluation capacity in the long-run.

The monitoring and evaluation process for EUSAIR has a couple of specific challenges. One is developing and implementing a system that can be nourished by data from all of the countries, each of which has different data gathering methods and capacity. The second is harmonising the data in order to create a synthetic and useful picture. In addition, the system should be able to "speak with" national monitoring and evaluation systems as well as those associated with the distinct Operating Programmes.

National-level monitoring and evaluation systems for EUSAIR in participating countries are currently realised on a rather informal basis. Strengthening this with a more structured mechanism - and supporting countries to build their ability to do so - would be desirable, and could involve other actors and organisations more accustom to performing such a task (e.g. academics, civil society organisations, etc.). In some countries, it may be a matter of adapting or further developing existing practices for policy and programme evaluation rather than establishing entirely new ones. Investing in capacity building for monitoring and evaluation within countries, for data collection and analysis, as well as in terms of shared or common monitoring and evaluation functions across the countries, could support stronger coordination and give greater insight into overall success. In addition to, and occasionally in place of, quantitatively-based monitoring and evaluation systems, qualitative reporting can also be valuable, especially when such reports receive high-level or political attention. Slovenia's National Coordinator annually reports to Parliament the year's accomplishments with respect to the macro-regional strategies. The National Coordinators' briefing to the President and Parliament about macro-regional events, within the context of the relevant parliamentarian conferences, is a complement to the annual

\footnotetext{
${ }^{6}$ In particular, this task is implemented by the Special Service for Strategy, Planning \& Evaluation of the National Coordination Authority within the Greek Ministry of Economy and Development, and is part of the Facility Point Work Package 3.

7 These monitoring procedures are expected to start in the first trimester of 2018 and will deliver annual implementation reports for each Pillar of the strategy, covering the implementation of the Pillar in all participating countries. The synthetic evaluation of EUSAIR as a macro-regional strategy could be delivered by mid-2019.
} 
report to Parliament. A report-based monitoring system is also in place in Sweden for its EUSBSR participation (Box 7).

\section{Box 7. Annual reporting for EUSBSR in Sweden}

As part of their EUSBSR participating, Sweden's 44 participating agencies submit an annual progress and implementation report to their ministries, indicating how their activities have contributed to the strategy in the previous 12 months. The Swedish Agency for Economic and Regional Growth (Tillväxtverket) then collects the reports, reads and analyses them, and finally compiles a report entitled "The Implementation of the EUSBSR in Sweden". This reporting tool has a number of associated benefits. The agency is forced to examine what they have done and what they can improve in the future. It is also a way to keep the strategy in the minds of management, ensuring that it is incorporated into the agency's work. Finally, it also serves as an aide memoire, helping to recall what has been accomplished thanks to the strategy. It has also served as a learning and strategic tool for Tillväxtverket as well as for the National Coordinator.

Source: Panel discussions, OECD EUSAIR Seminar "Strengthening National Coordination Mechanisms for EUSAIR", 2 October, 2018, Podgorica, Montenegro.

Communicating results to stakeholders via the Stakeholder Platform for the full strategy and on country-EUSAIR websites for government and non-government stakeholders, including citizens, could help illustrate value added. This would also support building ownership and strengthening accountability to all stakeholders.

\section{Managing the funding challenge}

Funding is a significant part of any governance framework. In accordance with the 3 No's, EUSAIR was established without an explicit or dedicated funding source. This said, it was also not based on a specific, existing EU funding instrument, but rather intended to permit countries to tap into a diversity of sources - both EU and national. This has fallen short of expectation, however, and while a dedicated funding source is potentially unnecessary, clearer support and guidance with respect to accessing existing funding would be beneficial.

\section{Funding sources are fragmented}

The issue with funding and its impact on governance is three-fold. First, is a high degree of fragmentation; and this itself is divided into two components. One is the fragmentation among potential funding sources. Not only are there multiple and diverse categories from which funds could be obtained - EU funds, national budgets, private sector, international finance and lending community, and other sources - within each of these categories there is often more than one potential source. In the case of EU funds, there are at least 12 different possibilities to consider ${ }^{8}$. Participating countries indicated that EU funds represented the largest potential "go-to" category (69\%), followed by national governments

\footnotetext{
${ }^{8}$ Countries identified the following funds as potential sources. $\%$ indicates the $\%$ of countries considering the fund a financing option: ERDF (excluding ETC, 10\%)), ETC (14\%), Cohesion Fund (5\%), ESF (7\%), EARDF (2\%), EMFF (4\%), IPA (14\%), WBIF (5\%), Connecting Europe Facility (5\%), LIFE (7\%), COSME (12\%), Horizon 2020 (15\%) (OECD Questionnaire 2017).
} 
(17\%) (Figure 2) (OECD questionnaire, 2017). Currently, ADRION is considered to be the most important funding source for EUSAIR ${ }^{9}$. This is despite its limited appropriations and scope - it is focused on supporting governance initiatives - and communication flows between ADRION and EUSAIR that are reportedly not as strong as they could be. Overall, this form of fragmentation is significant and can create confusion, increase administrative burden, and render competitive bidding even more challenging, especially when funding sources do not explicitly recognise the value added of EUSAIR projects.

Figure 2. EU Funds are the most turned to potential funding source

Answers to question: Please identify potential funding sources for EUSAIR

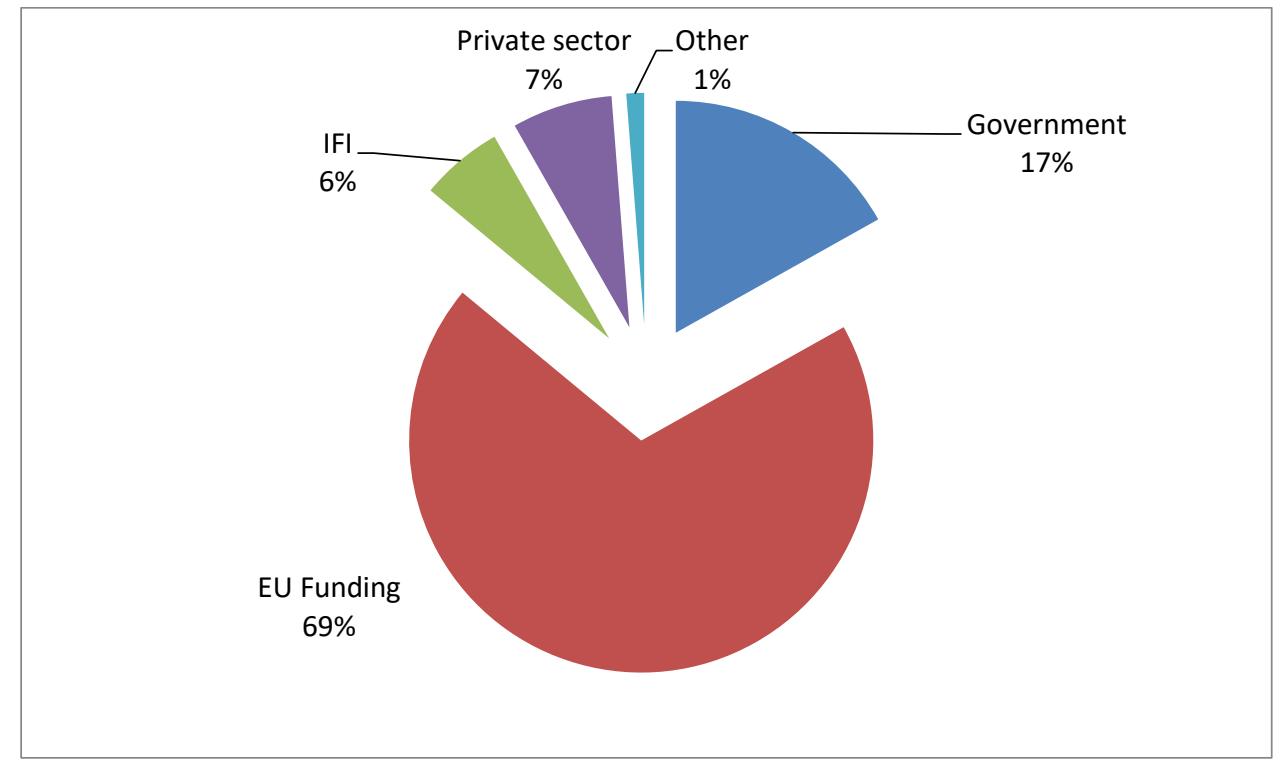

Source: OECD Questionnaire (2017).

The second form of fragmentation arises from the inherent differences in structure, regulations, timeframes and financial volume characterising funding mechanisms for EU and non-EU member countries (i.e. ERDF versus IPA II) ${ }^{10}$. This results in an imbalance with respect to accessible funding volumes, which in turn can create an asymmetry in generating and implementing projects.

A key point with respect to EUSAIR funding and how it is currently structured, is the limited role that national funding plays in directly supporting the strategy or implementing identified projects. Some countries are more active than others in using national funding, though it may be used more often to contribute to ensuring human resource capacity, particularly with respect to participation in strategy meetings and other activities, than financing specific EUSAIR projects. Beyond this, it is also difficult to quantify the potential impact that the numerous EU-funding sources (e.g. the Connecting Europe Facility

\footnotetext{
${ }^{9}$ The overall ADRION Programme budget is EUR 118 million (EUR 83.5 million from the ERDF, EUR15.7 million from IPA II, and EUR 18.8 million from national contributions) for transnational projects in the Adriatic-Ionian area (OECD case study; OECD interview).

${ }^{10}$ As an example, the ADRION Programme has EUR99 million allocated to participating EU member states for the duration of the programme, and EUR 15 million allocated from the IPA fund to non-EU member states (the equivalent of EUR 560000 annually per IPA country) (South-East Europe, n.d.).
} 
$(\mathrm{CEF})^{11}$, Horizon $2020^{12}$, COSME ${ }^{13}$, Life $^{14}$ ) have since they are not place-based or designed to directly support economic or social cohesion.

\section{Funding sources can be difficult to navigate}

A second challenge is identifying which fund (or funds) is most appropriate for a EUSAIR action, and then accessing it. Thus far, effort has concentrated on promoting sustained cooperation between ESIF and IPA programme authorities and EUSAIR countries ${ }^{15}$, meaning that ESIF, IPA and other relevant national and regional funding streams should be harnessed to advance meeting EUSAIR objectives. Participating countries have been challenged, however, to find mechanisms to coordinate and pool resources in order to fund relevant macro-regional projects. One issue is that ESIF programmes are nationally focused, making it more difficult to use funds to support transnational projects (COWI, 2017) unless such a scope is agreed upon earlier, as has been the case of EUSBSR ${ }^{16}$. This is compounded by the fact that ESIF programmes were developed and agreed upon prior to the introduction of EUSAIR. Another issue is that each funding mechanism and instrument has its own legal basis, eligibility criteria and selection procedures. This makes it particularly difficult for line ministries to coordinate and pool funds at a national level for projects that are also broadly European or transnational and require European or, at a minimum, cross-border coordination. In addition, it requires a good level of knowledge and capacity to identify and combine diverse sources of available funding, including national funds. Unfortunately, this is a capacity that is not sufficiently mature among all EUSAIR countries. When funding sources are identified or there is agreement on what to fund, the imbalance of resource levels available between EU member and non-EU member countries adds an additional layer of difficulty and can affect outcomes (e.g. the same road maybe of different quality in an EU member versus non-EU member country though its implementation is linked to the same project). Experience from EUSBSR indicates that some of these funding challenges smooth out when macro-regional strategies are incorporated into programmes from the outset - particularly when supported by EU Regulations requiring that macro-regional strategies be included in relevant programming from the outset (i.e. when priorities are identified and programmes are written).

11 The Connecting Europe Facility (CEF) promotes growth, jobs and competitiveness through targeted infrastructure investment for the development of high-performing, sustainable and efficiently interconnected trans-European networks in the fields of transport, energy and digital services (European Commission, 2018: https://ec.europa.eu/transport/themes/infrastructure/ten-t-guidelines/project-funding/cef_en).

12 Horizon 2020 is a potentially strong funding source given that R\&D is one of the strategy's cross cutting issues (European Commission, n.d.: https://ec.europa.eu/programmes/horizon2020/)

${ }^{13}$ COSME is a programme implementing the Small Business Act (SBA) which reflects the Commission's political will to recognise the central role of SMEs in the EU economy. This programme fits particularly well with the EUSAIR priorities for Pillar 4, related to tourism, since it encourages implementation of multi-country measures for diversification of tourism offer, fostering multi-national cultural and tourism routes etc. (European Commission, 2018: https://ec.europa.eu/growth/smes/cosme_en)

${ }^{14}$ EU countries are not eligible for funding under this Programme. Third countries can participate as partners and in such cases there is supplementary funding (European Commission, 2018, http://ec.europa.eu/environment/life/)

${ }^{15}$ In accordance with the Dubrovnik Declaration adopted at the 1st EUSAIR Forum in May 2016 and confirmed at the 2nd EUSAIR Forum in Ioannina in May 2017.

${ }^{16}$ It must be acknowledged that when introduced EUSBSR faced similar challenges as EUSAIR, particularly since it was launched once a programming period was underway, and thus intended to be "added" to existing programmes, much as is expected of EUSAIR. In the 2014-2020 programming period the strategy was incorporated in to programmes from the outset, supported by the EU regulation stipulating that macro-regional strategies must be included in relevant programmes when they are written and when priorities are established. 
Related to this challenge is an observation by countries that there is a need to compete with non-macro-regional projects for funding. This can be particularly difficult since Managing Authorities in EUSAIR countries have little incentive (and no requirement) to link their programmes to EUSAIR and share their funds. Countries also remarked that the preparation phase for EUSAIR projects is more costly, particularly since the processes in prepreparation and pre-conditions are different than those for other projects (so it is more difficult to "piggy-back" and there is a new learning curve to manage). The European Union strategy for the Danube Region has addressed the some of the initial project funding challenges with a number of different initiatives, including a Technical Assistance Facility grant, providing seed money, and creating opportunities to link projects with investors (Box 8). 


\section{Box 8. Addressing initial funding challenges in the Danube Region Strategy}

The Technical Assistance Facility for the Danube Region Projects (TAF-DRP) was an EU grant scheme implemented through calls from 2014 to 2016. Its objective was to support the transformation of project ideas into "bankable/fundable" project concepts ready to be implemented. Once the identified projects were sufficiently mature, they could be launched with their own resources or apply for funding from public and/or private donors and/or EU programmes. Experts were selected by the project management unit and then paired with the project proposer, as illustrated in the figure below.

Figure 3. The TAF-DRP process

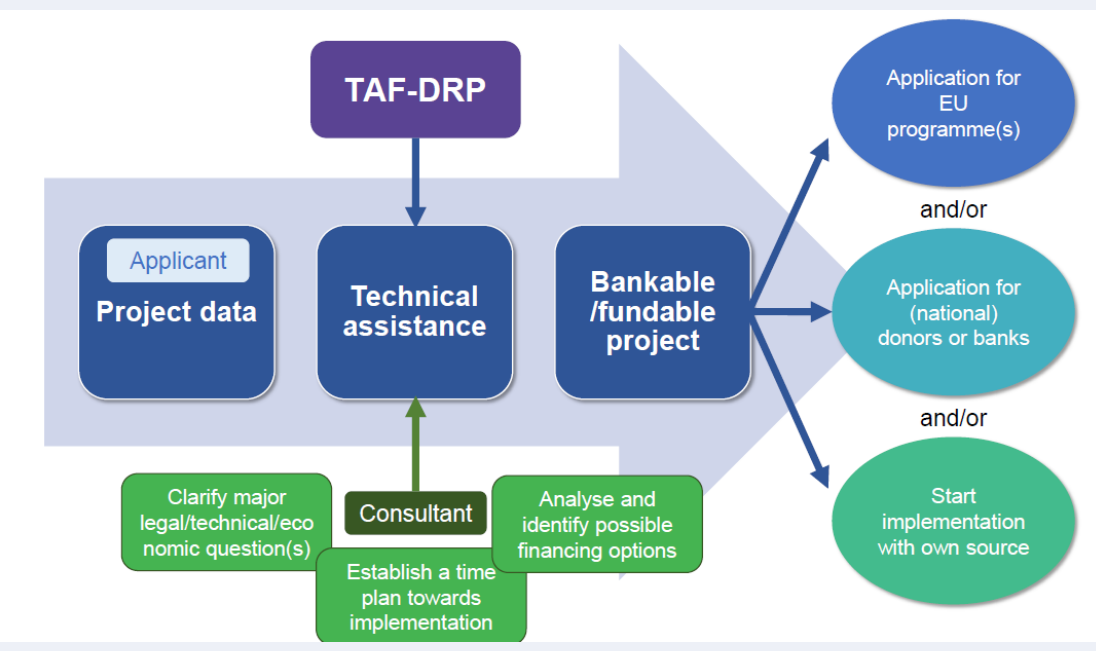

Source: Adapted from EUSDR, Priority Area 10, www.danube-capacitycooperation.eu/taf-drp

The START Danube Region Project Fund provided small grants for the development and implementation of Danube region projects. The grants came in the form of seed money to support either specific parts of a larger project, or a small project relevant to all priority areas. In principle projects had to involve at least two partners (public or private organisations) from two EUSDR participating countries. It was designed for small institutions, non-governmental and civil society organisations whose projects had a public interest, a macro-regional impact and addressed at least one EUSDR topic. START was funded $95 \%$ by the European Union and $5 \%$ by the City of Vienna. This project ended in 2016.

The Danube Strategic Project Fund (DSPF) fills the space left by TAF-DRP and START with funding that is also linked to cooperation. The focus is primarily on innovative, early-stage projects that respond to needs in the Danube functional area and which are not eligible for other funding. It is co-financed between by the European Parliament via the European Commission and the City of Vienna ${ }^{17}$.

Also part of the Danube Investment Framework, the Danube Financing Dialogue (DFD) was a pilot initiative consisting of a series of events bringing together SMEs from throughout the Danube Region, international financing institutions and national funding 
partners. The initiative, launched in 2012 has gone through five iterations, signalling a highly successful initiative.

Danube River rEsearch And Management (DREAM) is a good practice in fund integration for large infrastructure projects. It is managed by the Vienna BOKU University and is the first scientific EUSDR flagship project with combined investments totalling almost EUR 70 million. Since 2012, it has succeeded in combining funding from different sources and integrating scientific partners from 11 Danube countries (Austria, Bulgaria, Croatia, Czech Republic, Germany, Hungary, Moldova, Romania, Serbia, Slovakia and Ukraine). The project and its network of laboratories have received additional support through the Technical Assistance Facility (TAF) for Danube Region Projects and from the HORIZON 2020 Programme.

A number of these projects, particularly TAF-DR, DFD and START, are considered to have been effectively implemented. However, evaluators highlighted the importance of seed money to further support the development of projects that were linked to different EU funding schemes, and of building comprehensive management skills for project promoters. In addition, the experience with DFD underscored the need for more and better targeted communication in the business sector, which could be accomplished at least in part through local and regional events. Lessons emanating from the START programme included the value that small-scale funding represents, particularly for small and medium sized cities as well as civil society organisations, and a need for funding mechanisms that are associated with simplified implementation structures.

Source: "Stepping up Institutional Capacity and Cooperation", https://www.danube-capacitycooperation.eu Further information also in: A. Gnamus, F. B. Hegyi, S. E. Perez - Developing Danube R\&I Projects across Borders - How to Make the Joint Use of EU-Funds a Reality?, JRC Technical Reports - S3 Policy brief series nr. 10/2014, September 2014; https://www.danube-capacitycooperation.eu/start-overview; https://www.danube-capacitycooperation.eu/files/8; https://www.danube-capacitycooperation.eu/generalinformation-about-the-dspf; https://www.danube-capacitycooperation.eu/danube-financing-dialogue-dfd; https://www.danube-navigation.eu/projects/dream-danube-river-research-and-management http://www.ica-casee.eu/index.php/dream-european-reserach-facility; Danube Region Strategy (2016b), "EU Strategy for the Danube Region Implementation Report of EUSDR PRIORITY AREA 10: Stepping up Institutional Capacity and Cooperation - FINAL", Reporting period from 07/2016 to 12/2016, available at:

https://www.danube-capacitycooperation.eu/uploads/files/EUSDR_IR_07-12-2016_PA10_FINAL(1).pdf

\section{Resources dedicated to EUSAIR related activities are often limited}

A third problem is limited national funding to support internal EUSAIR governance structures and to get the strategy off the ground. Resource constraints have affected national participation in meetings, particularly at the TSG level ${ }^{18}$. Here the issue is also two-fold. One is that ministries in some countries do not have the resources to dedicate and a second is that sometimes internal rules restrict inter-ministerial financial transfers. This has made the appointment of Facility Points Project Partners in each country extremely valuable. Some countries have managed to overcome such constraints, though it has required

\footnotetext{
${ }^{17}$ It will be managed by Priority Area Coordinator 10 of the EUSDR (City of Vienna) in close cooperation with EuroVienna, affiliated entity to the City of Vienna.

${ }^{18}$ While this particular issue is being resolved through the Facility Point Project and Facility Point Project Partners in each country, and expected not to persist into 2018, it has represented a significant constraint in launching the strategy.
} 
additional government intervention ${ }^{19}$. Overall, however, the internal funding issue has affected the timeliness in launching essential support, such as the Facility Point Project Partners, the Stakeholder Platform that is intended to facilitate communication, and monitoring mechanisms. While delays may not be fully attributable to resource shortfalls, these are reported to be a contributing factor.

In general, given the lack of specific EU funding for EUSAIR, financing the implementation of the strategy from the general national budget is a significant challenge for most, if not all, countries. To better manage this, closer cooperation between management bodies of the strategies and the funds (generally those associated with mainstream programmes) would be helpful. In addition, consideration should be given to those projects that are deemed to have a transnational value. These could be funded in two ways, either by awarding additional credits for their macro-regional aspects when applying for funding, or by publishing targeted calls for projects that would work exclusively to achieve the goals of the macro-regional strategies. The lack of funds is a particular challenge in non-EU member countries who often struggle to find resources for co-funding. This can hinder the implementation of common projects.

Moving forward, it may not be that EUSAIR needs new or dedicated funds, or that funds are unavailable. However, it could benefit from greater clarity, flexibility, and support in accessing the funds that exist. Such support, particularly in the form of political consensus that EU funding sources, such as ESIF funds, should be aligned to, and possibly even developed in conjunction with, macro-regional strategies, including EUSAIR (COWI, 2017), would be of significant value. This consensus however, has yet to form.

\section{Human resource and capacity challenges}

Within the EUSAIR multi-level governance structures of each country, human resource challenges are particularly acute. Some of these challenges are shared by EU-member and non-EU member countries alike, while others are more country specific.

\section{Ensuring consistent levels of experienced staff}

All of the countries are experiencing significant limitations with respect to ensuring consistent levels of experienced staff, which manifests in at least two ways. First, is the turnover of qualified staff, often as a result of elections or institutional restructuring. When this happens, the process to replace staff can be lengthy and bureaucratic, leaving positions unfilled or filled temporarily by civil servants without the same level of expertise and institutional memory of their predecessor. This is not an issue that all countries face, but it is significant and troubling for those that do, and certainly affects overall capacity with respect to the strategy's implementation. It is particularly challenging for administrations that are struggling to build institutional and administrative capacities in critical sectors or areas, as well as those who strive to build knowledge in the area of EU territorial development and cohesion policies. The result, in addition to knowledge and staffing gaps, is additional burden on remaining staff, particularly those working in EU coordination, funding or integration structures.

\footnotetext{
${ }^{19}$ For example, in Slovenia the government decreed that ESIF technical assistance could be used on an ad hoc basis during the 2014-2020 programming cycle for activities associated with macro-regional strategies, including EUSAIR, as long as there was no support available from transnational cooperation programmes in the same period.
} 
Second, is staffing challenges in terms of numbers and the time they can dedicate, which appears endemic to all countries. EUSAIR is one of many responsibilities in the portfolios of the National Coordinators, Pillar Coordinators and TSG representatives. Consequently, the heavy workloads of the individuals involved can also prevent them from actively participating in the EUSAIR-related activities, at both national and subnational levels when relevant. Additionally, since the strategy is not associated with specific funds, governments rely on existing staff covered by existing budgets, which in many countries is already highly limited. In addition, the "no new funds" caveat means that relevant line ministries may see little advantage in prioritising EUSAIR or EUSAIR projects (there is no rapidly apparent funding advantage), thereby further limiting the amount of time that line ministry staff can dedicate to the strategy. Thus, very often the strategy's implementation is the result of a personal commitment or dedication by several key civil servants or professionals than that of an established system.

The limitations that arise from the human resource challenges often translate into a limitation in the capacity to develop, propose, and implement strategic projects reflecting EUSAIR priorities, and/or accessing EU funds. It also affects institutional memory, as well as accumulated and transferable knowledge.

\section{Strengthening links with EU, cross-border and national strategies and programmes}

The limited or lack of direct, ex ante links between EUSAIR and the goals established in the national development strategies, sector strategies, investment plans, and EU Operational Programmes (OPs), is another serious challenge for the multi-level governance of EUSAIR in all countries. It affects the ability to clearly identify the strategy's valueadded and limits its visibility when line ministries move to implement relevant policies and programmes. It also makes it more challenging when approaching the Managing Authorities to link EUSAIR to Operational Programmes or IPA funding opportunities. One problem that arises is a certain degree of competition for funds already earmarked for other programmes, and EUSAIR is perceived as potentially diverting funds.

\section{Strengthening links with other strategies and framework arrangements}

Ensuring links and greater alignment between EUSAIR and other EU as well as national and cross-border arrangements is important, in the short term and especially post-2020. If the current approach of linking EUSAIR project proposals to other EU programming arrangements for funding and implementation is to work, making the most of such complementarities is fundamental. It does, however, pose an additional coordination challenge that can be difficult to overcome for reasons outside the control of EUSAIR National Coordinators or the multi-level governance structures supporting EUSAIR in the participating countries.

\section{A need for stronger incentives to tie in with national planning documents}

First, there is difficulty to embed EUSAIR into national strategy, planning and framework documents - either for overall national development or for EUSAIR-relevant sectors (e.g. energy, transport, environment, tourism, etc.). Many national strategic development documents, including at a sector level, were agreed upon prior to the introduction of EUSAIR. Thus, while national aims are quite often compatible with and complementary to EUSAIR goals, there are few to no intrinsic links between the national and macro-regional strategies. These are often identified ex post. There are also few incentive mechanisms to ensure that national programming supports EUSAIR, and apparently little consideration or 
awareness that EUSAIR could help line ministries in participating countries meet their own national objectives. It is expected that in the next national programming period ex ante links will be easier to establish. This has been the experience in EUSBSR countries such as Poland and Sweden, where, in the latter, the macro-regional strategy has been integrated into the National Strategy for Sustainable Growth and Attractiveness (2015-2020). Until such a time that EUSAIR can link into national-level strategy or planning cycles, some acknowledgement of the complementarity between existing national planning documents and EUSAIR goals would be valuable in all cases.

\section{Aligning the various EU programming frameworks and EUSAIR}

Second, there is difficulty connecting with OPs as Partnership Agreements were based on policy papers developed by each country prior to the introduction of EUSAIR, and on the different thematic objectives that the country would co-finance. This leads to difficulties in matching EUSAIR projects with available and existing funds. Thus far, EU strategic papers and Partnership Agreements give general indications to programme authorities that consistency with EUSAIR needs to be ensured, and projects relevant to EUSAIR's thematic Pillars should be implemented. However, there are no provisions to incorporate EUSAIR in the implementation stage. One way around this is by channelling actions and initiatives through ESIF OPs as long as they are consistent with the expected results per policy and per thematic objective area in the programme. In other words, objectives should be aligned, and this is one of the key challenges. In the case of non-EU member countries, the Indicative Strategy Papers (ISP) and IPA II assistance documents were prepared prior to EUSAIR's launch and rarely reference EUSAIR. This is not to say that EUSAIR themes are not covered, they are just not explicitly mentioned, which can limit its visibility as a development tool. While this is a significant issue now, it could be tempered if the partnership agreements and programming documents negotiated for the post-2020 programming period explicitly mention the role of EUSAIR in connection with ESIF. It would also be helpful if more explicit selection criterial for EUSAIR projects linking to ESIF were established. Accomplishing this will require a proactive approach by key implementers and particularly national coordinators during the negotiations process - be they internal/national or EU-level.

Third, synergies, and the ability to build them, with ETC and Cross-Border Cooperation (CBC) programmes can be limited. ETC and CBC programmes can, and are, used to support the implementation of EUSAIR and coordination of relevant activities across borders. Part of their appeal is an ability to provide more readily accessible and compatible frameworks and financing opportunities, particularly in the case of the ADRION programme (which prepares targeted calls relevant and open to EUSAIR). Unfortunately, however, these initiatives are limited in their scope. For example, while ADRION funds are available for "soft" actions, such as feasibility studies, planning tools and other governance-related and innovative pilot initiatives, they cannot be applied to more costly projects, such as those related to infrastructure. $\mathrm{CBC}$ programmes generally involve two or three partner countries. While they can be useful for completing projects in a specific part of the EUSAIR region, they may have less impact on the macro-region overall and face financing challenges. Thus far, the possibility of a strategic and coordinated monitoring exercise among the multiple ETC and CBC programmes in the EUSAIR area has not been possible. Experience from the European Union Strategy for the Baltic Sea Region, where synergies were created around a specific topic rather than project, might be of value, either in the short or medium term (Box 9). 


\section{Box 9. Building strategic synergies around a common topic}

In the Baltic Sea macro-region, a flexible and advanced approach to cooperation for transnational research \& innovation (R\&I) was introduced into the Swedish Operational Programmes for 2014-2020 and is being tested with six pilot and joint projects. The application procedure supports open and flexible cooperation schemes that facilitate $R \& I$ cooperation between transnational partners and permits the addition of new partners to projects already underway. While own-financing by all the partners is preferable, it is not compulsory. The model has been widely promoted in order to ensure homogeneous implementation within the ESIF national/regional OPs of Baltic Sea Region member states and to further encourage EUSBSR cooperation (recurring to Article 70.2 of the Common Provisions Regulation).

Source: Gnamus, A., F. B. Hegyi, S. E. Perez (2014), Developing Danube R\&I Projects across Borders How to Make the Joint Use of EU-Funds a Reality?, EC - JRC Technical Reports - S3 Policy brief series nr. 10/2014, September 2014; Macro-Regional Strategies in the ESI Operational Programmes 2014-2020 proposal for a Transnational Cooperation Component to support the implementation of the EU Strategy for the Baltic Sea Region - EUSBSR, Concept Paper of the Swedish Agency for Economic and Regional Growth, 1/2014).

One of the consequences of the gap in timing between the launch of EUSAIR and the negotiation, agreement and implementation of 2014-2020 programming documents ${ }^{20}$ is difficulty for the various programmes to take the macro-regional strategy on board. Part of the problem is a misalignment in programming and eligibility rules for project identification, selection, funding and implementation, as these can vary across programming instruments. Created before EUSAIR, they could not take the strategy into account, resulting in limited complementarity. The labelling discussion has been taken up as one way to address this matter, and there is activity in TSG 2 (transport) with respect to labelling, including an open list of labelled project proposals. Overall, however, there is limited agreement among the countries with respect to the process (Box 10). In addition, the lack of strong connection between EUSAIR and EU OPs can restrict the possibility that the labelling process lead to concrete funding opportunities.

${ }^{20}$ These include regulations, OPs, Partnership Agreements, and Indicative Strategy Papers for IPA II countries. 


\section{Box 10. The challenging question of labelling}

The issue of labelling has both a technical and political dimension. Politically, labelling is good for visibility, and technically it can help overcome some of the programming and financing challenges. However, it does not help in promoting the design or implementation of EUSAIR-specific actions. There has been no decision made yet on the matter of labelling, but in its current iteration the discussion revolves around the TSGs. It has been proposed that a few guiding principles be established, setting out milestones in the process of identifying projects of macro-regional importance, i.e. those that contribute to the objectives articulated in the EUSAIR action plan. The guidelines would provide assistance to TSGs in a two-step labelling process (pre-screening of candidate projects followed by screening in accordance with a protocol unique to each TSG. While the process should remain flexible, this approach can lead to significant differences in approach by the four TSGs, and to date has not resulted in a consensusbased list of labelled projects. One of the challenges confronting a potential labelling process is that it is currently difficult to argue that these interventions do not add value to the macro-region, and it is also difficult to point to concrete evidence that EUSAIR projects have materialised only thanks to the macro-regional strategy. Moving forward, ex ante labelling may be more easily realised in some instances through projects identified and funded by the Facility Point Plus initiative.

Source: EUSAIR, Working paper regarding the establishment of a sustained dialogue between the Eusair and the ESIF Programmes. Labelling and funding EUSAIR Projects, January 2017; Slovenia National Coordinator, EUSAIR TSG 3 workshop proceedings: "How to translate synergies between MSP and ICZM into concrete projects" including "Interpillar draft matrix", Mediterranean Coast and EU Macro-regional Strategies Week, Slovenia, 20-23/9/2017

The need to link EUSAIR initiatives with the programming opportunities associated with OPs, IPA II, ETCs, CBCs, etc. is a significant challenge and in the future may require greater flexibility and stronger partnership incentives for Managing and Programming Authorities. The challenges, which arise from having the various programmes unlinked since their inception, is beyond the control of each individual participating country, and is more guidance or assistance from the European level may be needed to overcome these in the short term. In the longer term, consideration should be given as to how to ensure links between EUSAIR and other European framework initiatives for EU-member and non-EU member countries.

Regular dialogue and contact to discuss priority projects would be advisable between National Coordinators, Pillar Coordinators and Managing and Programming Authorities as this could be helpful to establish stronger ties and identify areas of common interest and intent.

\section{Better leveraging the "strategy" dimension of EUSAIR}

Strategies can be powerful coordination mechanisms, helping identify priorities, align interests and provide a road map for action. However, they are not always concrete and thus it is harder to articulate their value added - a challenge voiced by all participants. As a macro-regional strategy, one of EUSAIR's core goals is to improve coordination among EU policies and programmes in a cross-sector and cross-border basis. This objective is 
proving difficult to realise in part because the sector policies that support EUSAIR Pillars are part of established policy networks and implementation channels that are not necessarily structured to function in a cross-sector and multi-country manner (COWI, 2017). This is further compounded by a tendency to approach EUSAIR as means to promote projects rather than as a strategy to align policy objectives the relevant projects to realise these. Work may need to be done to improve the capacity of participating countries to use EUSAIR strategically, coalescing around very concrete aims, identifying policy interventions, and using the strategy to further enhance the policy relevance of national and cross-border programmes and initiatives (INTERACT, 2017).

The panoply of topics and projects that can be implemented through EUSAIR in support of its thematic objectives vary from large, costly infrastructure projects (for example in Pillar 2), to softer infrastructure projects (particularly the case of Pillars 3 and 4), or a combination of these (especially Pillar 1). Because the various themes and types of projects may require different methodological inputs, for cross-sector coordination to work there needs to be some agreement and alignment as to how objectives are best achieved (e.g. through a macro-regional policy approach, through individual but coherent national strategies, etc.). It is also necessary to make sure that these objectives are coherent with those of the relevant counterparts who will be implementing the project(s) (e.g. national or subnational administrations, non-government stakeholders, etc.). If these counterparts are not involved from the beginning, the process can be more difficult.

\section{Subnational and other stakeholder engagement}

Engaging at the subnational level with government and non-government stakeholders is fundamental to the success of the strategy, since it is at the regional and local levels where implementation occurs. Most case studies highlighted a low degree of formal subnationallevel (regional where relevant, and municipal) involvement in the implementation of EUSAIR. Informally there may be more exchange, but formal vertical information flows appear limited overall, affecting awareness of the strategy. Two countries, Greece and Italy, have legal frameworks requiring engagement with the regional level, and have actively and formally engaged their regional levels in the strategy's implementation. However, as in the other six participating countries, engagement with local governments, the private sector and civil society is limited to consultation rather than more active participation in the strategy's implementation. This is likely to change as the strategy matures and/or if some of its funding challenges are solved, yet there is a larger, two-fold obstacle. First, locallevel stakeholders perceive EU initiatives as another funding source, which is not the case with EUSAIR. Second, there is limited capacity at the subnational level to develop project proposals meeting EU guidelines and also to identify the potential funding sources. Thus, National Coordinators feel hamstrung with respect to subnational, and particularly locallevel, stakeholders: they cannot offer funding, and if they receive a relevant project proposal, the process to receive funds is not guaranteed since it is not entirely in their hands, and it can be more burdensome than local capacity can absorb. Possible practices countries could consider in order to help manage this come from Albania, Greece and Slovenia (Box 11). While this may not fully solve the problem, it could create more opportunity for subnational level involvement. Pillar 2's transport master plan methodology may also establish a clearer path for engagement by subnational authorities. 


\section{Box 11. Building awareness of EUSAIR at the subnational level in Albania, Greece and} Slovenia

Through the Special Network of Local Points per Managing Authority of European Structural and Investment Fund (ESIF) programmes, Greece consults with local and regional authorities and other stakeholders to ensure the compatibility of EUSAIR and European Territorial Cooperation Strategies with national and regional priorities. This is in keeping with the European Code of Conduct for Partnership in ESIF implementation. The Network represents the link between Managing Authorities and the National Pillar Coordinator. Through it, Greece has made significant effort in subnational implementation via already established mechanisms - i.e. those in place for the delivery of ESIF programmes - and political-level commitment to the strategy's implementation.

In Albania, the government cooperates with the Albanian School of Public Administration (ASPA) to organise an annual training course for subnational entities on projects and available funding for investment and development.

In Slovenia, the national coordinator for macro-regional strategies, in collaboration with the team from the Mediterranean Coastal initiative, plus 30 institutions, and in the context of the EU Macro-Regional Strategy Week sponsored an initiative to work with school children on an environmental "Clean-up the Beach" day. This action included a media conference to help educate citizens, and build awareness among subnational stakeholders (e.g. private sector, civil society organisations, and academia) and the media of the macro-regional strategies, especially EUSAIR, as well as other European initiatives in Slovenia with an environmental theme. Slovenia's participation in a "Youth for Europe" initiative, designed by the national coordinator in collaboration with NGOs and the EUSAIR Facility Point, emphasised sharing with children the value of macroregional cooperation, and a "Drawing the Future of the Coastal Road" collaborative event between NGOs and TSG 3, brought together citizens of all ages to share their ideas on how to use Slovenia's coastal area in a more sustainable manner.

It is generally agreed among participating countries that greater mobilisation of the subnational level actors and non-government stakeholders is necessary. They can be key contributors in identifying priorities and developing innovative projects to realise EUSAIR objectives. Formally and substantially involving the subnational level in thematic discussions regarding EUSAIR can build the awareness and interest of local governments and other stakeholders in the strategy, leading also to building capacity and skills. The Stakeholder Platform and the Facility Points can play a strong role in addressing the challenges in this area, and Slovenia's early experience with the Facility Point may provide good examples. Increasing stakeholder involvement could also support wider ownership among subnational administrations. To strengthen their participation, structured workshops on EUSAIR partnership could be useful.

\section{Looking ahead: conclusions and recommendations}

Among EUSAIR participants, the strategy represents an important and valuable opportunity for growth and development in a collaborative format. At the same time, it faces challenges that are linked to its own governance and structures, as well as limitations arising in each participating country. Fragmentation and early delays have stifled progress, 
which can undermine the strategy's initial potential and make it more difficult to build ownership among national and subnational stakeholders. In addition, the complexity (and in some cases the lack of clarity) of governance structures, funding mechanisms and implementation procedures pose barriers to success, which could be overcome with the introduction of greater simplicity and streamlining (European Parliament, 2018).

The preparation of the EU legislative framework and programming cycle for the post-2020 period represents an important opportunity to reassess and address the challenges identified. Simplifying and strengthening governance structures and coordination mechanisms will be critical. Ensuring greater alignment and establishing stronger links and incentives to cooperate between EU programming and framework arrangements and EUSAIR will also be valuable in a second stage.

The effectiveness of the strategy's implementation is clearly linked to the way EUSAIR member countries secure or coordinate funding opportunities. While the positive dimension is that there are many potential funding sources, greater clarity and guidance is necessary on how to navigate these, particularly for non-member countries. Better alignment between EUSAIR and other EU programming initiatives, particularly with respect to the rules for funding, selection criteria, project eligibility and implementation will be important for success. This has represented a serious hurdle for the effective implementation of the strategy.

Despite its challenges, EUSAIR has strong potential to be a driver for sustained growth, a generator of opportunities, and a catalyst for greater environmental awareness and sustainability. To help countries and the strategy realise the macro-region's potential, the OECD has developed a series of recommendations for action (Box 12). It is recognised that some of these recommendations cannot be implemented immediately, or even in the short term, but may need to be taken into consideration for the next programming period. 


\section{Box 12. Recommendations to support more effective multi-level governance of EUSAIR} among all participating countries

The analysis carried out through the eight case studies on multilevel governance for EUSAIR implementation highlighted some common critical points, for which the OECD puts forth the following recommendations:

\section{For stronger ownership of the strategy}

- Identify large scale and/or significant projects and common objectives based on a shared vision at the EUSAIR national coordination level, involving representatives from all levels of strategy coordination and government.

- Build awareness of the strategy and its value added by focusing on strategic communication throughout the strategy's coordination structure, and beyond, including by:

-- Launching the Stakeholders Platform as soon as possible, and complementing it with a single-point-of-entry country specific portal for EUSAIR.

-- Ensuring that the Stakeholders Platform can be adapted to changing needs and contexts, and that it receives strong and continuous coordination support of the Governing Board and National Coordinators.

-- Provide information regarding EUSAIR on Cohesion Policy and Pre-accession web portals.

-- Strengthening stakeholder participation through communication actions and events that foster the involvement of subnational governments, as well as nongovernment stakeholders, including citizens.

- Build ownership of EUSAIR among different levels of government, ensuring clear mandates and lines of accountability.

\section{For stronger multi-level governance structures}

- Ensure ongoing involvement by all levels of the multi-level governance chain, from the European to the subnational, including:

-- Clearer attribution of responsibilities and expectations between EUSAIR (and its coordinating structures) and Operational Programmes/Managing Authorities and IPAII/Programming Authorities.

-- Continued guidance (stewardship) by the European institutions to ensure necessary European-level commitment, to guide the strategy's development, and support implementation processes.

-- A clearer commitment to and prioritisation of the strategy by relevant EU and national stakeholders, both political and technical.

-- A clearer articulation of roles and responsibilities within EUSAIR's coordinating structures, particularly between strategic versus operational/technical and administrative decisions,

-- Clarifying the role, breadth of responsibilities and degree of strategic decision making power of the Governing Board. 
-- Clarify and better harmonise what is expected from the distinct coordinating groups, particularly at the Pillar/TSG levels and with respect to their work on strategies and projects.

- Breakdown silos within the pillar structure by promoting greater information exchange, horizontally and diagonally, especially at the Pillar and TSG levels, also within countries.

- Ensure continuous support (resource and capacity) for the Facility Point, so that:

-- The Facility Point project is an ongoing endeavour for the overall strategy

-- Facility Point Project Partners within countries are resourced with capacitated staff

-- The role, responsibilities and expectations of Facility Point Project Partners are clear with respect to their contribution to EUSAIR

-- There is a level of harmony in the responsibilities of Facility Point Project Partners across the network, while also permitting for differences in country needs and contexts.

-- Promote regular exchanges or platforms for discussion among the eight incountry Facility Point Project Partners and ensure that information is communicated to Facility Point partners on a regular and timely basis.

\section{For more effective cross-sector, vertical and horizontal coordination}

- Build cross-sector coordination to capitalise on the inherent synergies among the four pillars, by:

-- Developing national-level incentive structures to encourage cross-sector dialogue and cooperation to support Strategy implementation.

-- Establishing consistent and homogeneous criteria for EUSAIR projects in line with the national strategic priorities (i.e. aligned with the single project pipeline, national strategies, etc.)

-- Supporting stronger coordination between EUSAIR and Managing/Programming Authorities of EU funds, including via a consultation mechanism for the regular assessment of and updating of the initial EUSAIR project list in each pillar.

- Strengthen horizontal coordination including by:

-- Establishing inter-ministerial committees or working groups where these are not already in place

-- Holding regular (bi-annual) cross-sector EUSAIR meetings with all key national and subnational actors to discuss priorities, identify opportunities, address problems, and prepare a common national position for each thematic area.

-- Building cooperation and dialogue with counterparts in operational programmes. 
- Build vertical coordination capacity expanding on dialogue opportunities with subnational authorities, including associations of subnational authorities.

- Develop stronger ties with other macro-regions, particularly in those countries or regions that are only involved in EUSAIR and at the Pillar and TSG levels for all countries, this can facilitate peer learning, identify common challenges and solutions, avoid potential duplication of work, etc.

- Ensure national level capacity for monitoring and evaluating the strategy overall and at the national level, by:

-- Being realistic about the data that are available, and the degree to which they can be harmonised for comparability. To the extent possible use already existing databases and platforms.

-- Designing national level monitoring and evaluation mechanisms that can support positive communication of results with government and non-government stakeholders, including output (and to the extent possible) outcome indicators based on realistic targets.

-- Using results to strengthen, update, modify or adjust the strategy at the macroregional level as well as dedicated implementation programmes and projects in each country.

\section{To support taking full advantage of funding opportunities}

- Create a practical, easy to use funding overview guide to support a better understanding of the different funding sources, their criteria, expectations and funds available.

- Promote greater flexibility in accessing EU funds in the next programming period by ensuring better alignment of project development, selection, implementation and impact criteria.

- Consider introducing early funding tools, using the EUSDR as a basis. This could include

-- Technical assistance funds, potentially via the Facility Point Project Partners.

-- Identifying seed money opportunities

-- Promote "match-making" possibilities between projects and investors, including international finance institutions, such as the European Investment Bank

- Build greater understanding and capacity to identify complementarities and opportunities by ensuring more regular dialogue with managing authorities and EUSAIR coordination structures. The Baltic Sea Region Managing Authorities Network could be a model.

- Better align rules and mechanisms for funding, resource mobilisation and their possible combination across ESIF and other EU funding mechanisms, IPA, and financial institutions, in order to allow for an efficient and effective allocation of resources - most easily accomplished in the next programming period. 


\section{To strengthen human resources}

- Enable shared learning, support specific training and exchanges between countries and among sectors through already existing tools (e.g. Taiex, light twinnings, and exchanges among EUSAIR participating countries and countries involved in other macro-regional strategies).

- Strengthen political commitment led by the European level to promote adequate financial and human resources for the strategy's implementation at the country level.

- Support project planning and implementation capacity as well as the ability to identify funding and co-funding opportunities, especially by non-EU countries.

\section{To better capitalise on synergies with other strategies and planning documents}

- Identify and focus on large impact projects that can address macro-regional challenges and produce multiplier effects by reviewing projects proposed under EUSAIR and selecting flagship projects. This could help secure the required commitments for implementation through the Managing/Programming Authorities of mainstream ESIF programmes and IPA programmes.

- Integrate macro-regional and transnational criteria into the evaluation of national projects, including by:

-- Bringing EUSAIR representatives into the process of identifying and evaluating relevant projects, ensuring calls are announced in advance and open according to an agreed upon schedule.

- Improve communication and information flows with other large EU initiatives, specifically ADRION, by:

-- Including EUSAIR Governing Board representation on the Monitoring Committee of the ADRION programme.

- Consider reframing the EUSAIR communication so that it is clear to interministerial stakeholders how the strategy is advantageous to them and can help them meet their own national, sector policy objectives.

- Identify and offer incentives to mainstream programmes to take EUSAIR projects on board, including through:

-- Flexible or additional quotas to projects offering the possibility of real spillovers beyond the territories of origin. Accomplishing this may require simplified rules and mechanisms at the technical level.

-- Rewards mechanisms when resources (ESIF, IPA, national and other funds) are mobilised for financing projects aiming to address the same strategic issues and that complement activities in one or more EUSAIR countries.

-- Clarifying and coming to a decision on the labelling issue: what it represents, what it entails, its specific requirements, etc.

- Ensure better alignment of timing between EUSAIR and the development of EU programming documents, so that EUSAIR objectives are clearly integrated into the operational programmes. 
- Better connect EUSAIR to ESIF frameworks in the post-2020 period and ensure that new partnership agreements and OPs are aligned with EUSAIR, by:

-- Elevating EUSAIR to the position of an umbrella strategy - similar to Europe 2020 - with OPs and other frameworks as implementation tools, rather than EUSAIR being considered another programme that needs to align to framework agreements.

-- Incorporating EUSAIR objectives into the priorities and commitments of the programming agreements, together with an upgrading of coordination mechanisms (e.g. focal network, communication platforms, etc.).

-- Building a reward system so that any obligation to invest macro-regionally is coupled with an award when agreement is reached.

\section{For more integrated and engaged subnational and non-government stakeholders}

- Consider involving stakeholders early on in the design and drafting of relevant strategy documents, particularly in preparation for the new programming period.

- Regularly incorporate a broad range of stakeholders in thematic discussions regarding EUSAIR, building awareness and interest of local governments and other stakeholders in the strategy, leading also to building capacity and skills.

- Sponsor or collaborate in public awareness activities to educate citizens to the themes of EUSAIR (e.g. environmental quality) while also building awareness of the strategy among subnational stakeholders (including private sector actors). 


\section{References}

Adriatic-Ionian EU (2018), "About EUSAIR", EU Strategy for the Adriatic-Ionian Region, available: http://www.adriatic-ionian.eu/about/the-adriatic-ionian-region

Conferenza delle Regioni e delle Province Autonome (2013), "Organizzazione del Gruppo per la strategia macroregionale Adriatico-Ionica (EUSAIR/Italia) della Conferenza delle Regioni e delle Province autonome", 13/080/CR11/C3, Rome, Italy, available at: http://www.regioni.it/newsletter/n2313/del-31-07-2013/strategia-macroregionale-adriatico-ionica-lorganizzazione-del-gruppo-11473/

Council of the European Union (2014), "Council Conclusions on the European Union Strategy for the Adriatic and Ionian Region (EUSAIR) ", General Affairs Council Meeting, 29 September 2014, Brussels, Belgium, available at: http://ec.europa.eu/regional policy/sources/cooperate/adriat ionian/pdf/council 29092014 en.pdf

COWI (2017), "Study on Macro-Regional Strategies and their Links with Cohesion Policy: Final Report", European Commission Directorate General Regional and Urban Policy, COWI, Kongens Lyngby, Denmark, available at: http://ec.europa.eu/regional_policy/en/information/publications/studies/2017/macro-regionalstrategies-and-their-links-with-cohesion-policy

COWI (2017), "Study on Macro-regional Strategies and Their Links with Cohesion Policy—Data and Analytical Report for the EUSAIR", Kongens Lyngby, November 2017, available at: http://ec.europa.eu/regional_policy/sources/cooperate/adriat_ionian/pdf/eusair_links_cohesion_policy .pdf

Dipartimento per le Politiche di Coesione (2017), PCM, Quadro di coerenza programmatica dei Programmi Nazionali, Regionali e di cooperazione territoriale europea 2014-2020 cofinanziati dai fondi SIE con la strategia per la regione Adriatico-Ionica (EUSAIR), 26/1/2017, Rome, Italy,

Dipartimento per le Politiche di Coesione (2017), PCM, Rapporto sull'Incontro di Dialogo tra le AdG dei Programmi Nazionali, Regionali e di Cooperazione Territoriale 2014-2020 cofinanziati dai Fondi Sie e i key implementers di Eusair, 26/1/2017 Rome, Italy,

European Commission (2018a), "Infrastructure - TEN-T - Connecting Europe: Connecting Europe Facility", official website, https://ec.europa.eu/transport/themes/infrastructure/ten-tguidelines/project-funding/cef en

European Commission (2018b), "COSME. Europe's programme for small and medium-sized enterprises", Entrepreneurship and SMEs, official website, https://ec.europa.eu/growth/smes/cosme_en

European Commission (2018c), "Environment LIFE Programme", official website, http://ec.europa.eu/environment/life/

European Commission (2016a), "Report on the implementation of EU macro-regional strategies", COM (2016) 805 final, 16 December 2016, European Commission, Brussels, Belgium, available:

http://ec.europa.eu/regional_policy/sources/cooperate/macro_region_strategy/pdf/report_implem_mac ro_region_strategy_en.pdf 
European Commission (2016b), "Commission Staff Working Document Accompanying the document on the implementation of EU macro-regional strategies", SWD(2016)443 final, Brussels, Belgium, 16 December 2016, available at:

http://s3platform.jrc.ec.europa.eu/documents/20182/154972/Commission+Staff+Working+Document/ c7bbcc09-ab34-48ac-8bda-c55b67da9cb4

European Commission (2015), "Research and Innovation Initiative for Blue Jobs and Growth in the Mediterranean Areas-Strategic Research and Innovation Agenda", the BLUEMED Initiative Document, Brussels, 16 September 2015, available at: http://www.bluemed-project.eu/wpcontent/uploads/2016/12/Bluemed-SRIA_A4.pdf

European Commission (2015), "Communication from the Commission to the European Parliament the Council, the European economic and Social Committee and the Committee of the Regions concerning a European Union Strategy for the Alpine Region", COM(2015)366 final, Brussels, 28 July 2015, available at:

http://ec.europa.eu/regional policy/sources/cooperate/alpine/eusalp communicationtion en.pdf

European Commission (2015), "Communication from the Commission: Investing in jobs and growth Maximising the contribution of European Structural and Investment Funds", including Annexes (I: European Territorial Cooperation/Interreg; II: Country fiches; III: Overall assessment of additionality; IV: Timing of submission and adoption of partnership agreements and programmes),

COM/2015/0639 final, Brussels, 14 December 2015, all available at: http://www.ipex.eu/IPEXLWEB/dossier/document/COM20150639.do

European Commission (2014), "Commission Staff Working Document - Action Plan, Accompanying the document "Communication from the Commission to the European Parliament, the Council, the European Economic and Social Committee and the Committee of the Regions concerning the European Union Strategy for the Adriatic and Ionian Region““", SWD(2014) 190 final, Brussels, 17 June 2014, available at:

http://ec.europa.eu/regional_policy/sources/cooperate/adriat_ionian/pdf/actionplan_190_en.pdf

European Commission (2014), "Commission Staff Working Document - Supportive Analytical Document, Accompanying the document "Communication from the Commission to the European Parliament, the Council, the European Economic and Social Committee and the Committee of the Regions concerning the European Union Strategy for the Adriatic and Ionian Region"", SWD(2014) 191 final, Brussels, 17 June 2014, http://ec.europa.eu/regional_policy/sources/cooperate/adriat_ionian/pdf/supp_analytical_doc_17june. $\underline{\mathrm{pdf}}$

European Commission (2014), "Communication from the Commission to the European Parliament, the Council, the European Economic and Social Committee and the Committee of Regions concerning the European Union Strategy for the Adriatic and Ionian Region", COM (2014) 357 final, Brussels, 17June2014, available at: http://ec.europa.eu/regional_policy/sources/cooperate/adriat ionian/pdf/com 357 en.pdf

European Commission (2014), "For a Prosperous and Integrated Adriatic and Ionian Region", Brussels, available:

http://ec.europa.eu/regional_policy/sources/cooperate/adriat_ionian/pdf/brochure_250914.pdf

European Commission (2014), "Report from the Commission to the European Parliament the Council, the European economic and Social Committee and the Committee of the Regions concerning 
governance of macro-regional strategy, (COM(2014)0284), Brussels, 20 May 2014, available at: http://eur-lex.europa.eu/legal-content/EN/TXT/PDF/?uri=CELEX:52014DC0284\&from=FR

European Commission (2014), "Summary of the 'Partnership Agreement' with Greece, 2014-2020, Brussels, 23 May 2014, available at: https://ec.europa.eu/info/sites/info/files/partnership-agreementgreece-summary-may2014 en.pdf

European Commission (2014), "Summary of the Partnership Agreement for Croatia, 2014-2020", Brussels, 30 October 2014, available at: https://ec.europa.eu/info/publications/partnership-agreementcroatia-2014-20_en

European Commission (2014), "Summary of the Partnership Agreement for Italy, 2014-2020", Brussels, October 2014, available at: https://ec.europa.eu/info/sites/info/files/partnership-agreement-italysummary-oct2014 en.pdf

European Commission (2014), "Summary of the Partnership Agreement for Slovenia, 2014-2020", Brussels, 30 October 2014, available at: https://ec.europa.eu/info/sites/info/files/partnershipagreement-slovenia-summary-oct2014_en.pdf

European Commission (2014), "The European code of conduct on partnership in the framework of the European Structural and Investment Funds", Directorate-General for Employment, Social Affairs and Inclusion, January 2014, available at: http://ec.europa.eu/esf/BlobServlet?docId=443\&langId=en

European Commission (2012), "Commission Staff working document, Elements for a common strategic framework 2014 to 2020 the European Regional Development Fund the European Social Fund, the Cohesion Fund, the European Agricultural Fund for Rural Development and the European Maritime and Fisheries Fund", SWD(2012) 61 final Part I, Brussels, 14 March 2012, available at: http://ec.europa.eu/regional_policy/sources/docoffic/working/strategic_framework/csf_part1_en.pdf

European Commission (2012), "Commission Staff working document, Elements for a common strategic framework 2014 to 2020 the European Regional Development Fund the European Social Fund, the Cohesion Fund, the European Agricultural Fund for Rural Development and the European Maritime and Fisheries Fund", SWD(2012) 61 final Part II Annexes, Brussels, 14 March 2012, available at: http://ec.europa.eu/regional_policy/sources/docoffic/working/strategic_framework/csf_part2_en.pdf

European Commission (2012), "Communication from the Commission to the European Parliament the Council, the European economic and Social Committee and the Committee of the Regions concerning the European Union Strategy for the Baltic Sea Region", COM(2012) 128 final, Brussels,23 March 2012, available at: http://ec.europa.eu/regional_policy/sources/docoffic/official/communic/baltic/com_baltic_2012_en.pdf

European Commission (2010), " Annex III Organisation of Work - European Union Strategy for the Baltic Sea Region - Interim Report on the implementation of the EU Strategy for the Baltic Sea Region", October 2010, available at: http://ec.europa.eu/regional policy/en/information/publications/reports/2010/report-theimplementation-of-the-eu-strategy-for-the-baltic-sea-region

European Commission (2010), "Communication from the Commission to the European Parliament, the Council, the European Economic and Social Committee and the Committee of the Regions concerning the European Union Strategy for the Danube Region", COM(2010) 715, Brussels, 08 
December 2010, available at: http://eur-

lex.europa.eu/LexUriServ/LexUriServ.do?uri=COM:2010:0715:FIN:EN:PDF

European Commission (2010), "Staff working document, Action plan accompanying document to the communication from the Commission to the European Parliament, the Council, the European economic and Social Committee and the Committee of the Regions, European Union Strategy for the Danube Region", COM(2010) 715 final, Brussels, 8 December 2010, available at: http://eurlex.europa.eu/LexUriServ/LexUriServ.do?uri=COM:2010:0715:FIN:EN:PDF

European Commission (2009), "Communication from the Commission to the European Parliament, the Council, the European Economic and Social Committee and the Committee of the Regions concerning the European Union Strategy for the Baltic Sea Region", COM(2009)248 final, Brussels, available at:

http://ec.europa.eu/regional_policy/sources/docoffic/official/communic/baltic/com_baltic_en.pdf

European Commission (n/d), "Horizon 2020", official website,

https://ec.europa.eu/programmes/horizon2020/

European Committee of Regions (2017), "Opinion: The implementation of macro-regional strategies", COTER-VI/029, 126th plenary session, 30 November and 1 December 2017, available at: http://edz.bib.uni-mannheim.de/edz/doku/adr/2017/cdr-2017-2554-en.pdfEuropean Parliament (2015), "Resolution on an EU strategy for the Adriatic and Ionian Region", 2014/2214(INI), 28 October 2015, OJ C 355/23 of 20/10/2017, Brussels, available at: http://www.europarl.europa.eu/sides/getDoc.do?pubRef=-//EP//NONSGML+TA+P8-TA-2015$\underline{0383+0+\mathrm{DOC}+\mathrm{PDF}+\mathrm{V} 0 / / \mathrm{EN}}$

European Parliament (2018), "Implementation of EU Macro-Regional Strategies: European Parliament Resolution of 16 January", 2017/20140(INI), Brussels, available at: http://www.europarl.europa.eu/sides/getDoc.do?pubRef=-//EP//NONSGML+TA+P8-TA-20180002+0+DOC+PDF+V0//EN.

European Parliament (2017), "Report on the implementation of EU macro-regional strategies (2017/2040(INI)", Committee on Regional Development, A8-0389/2017, 01 December 2017, available at: $\mathrm{http}: / / \mathrm{www}$.europarl.europa.eu/sides/getDoc.do?pubRef=//EP//NONSGML+REPORT+A8-2017-0389+0+DOC+PDF+V0//EN

European Parliament (2015), "New Role of Macro-Regions in European Territorial Cooperation", Directorate-General for Internal Policies, Department B: Structural and Cohesion Policies, Regional Development study Part I, January 2015, available at: http://www.europarl.europa.eu/RegData/etudes/STUD/2015/540349/IPOL_STU(2015)540349 EN.p $\underline{\mathrm{df}}$

European Parliament (2015), "Research for REGI Committee - Adriatic and Ionian region: SocioEconomic Analysis and Assessment of Transport and Energy Links", Directorate-General for Internal Policies, Department B: Structural and Cohesion Policies, Regional Development study, December 2015, available at: http://www.europarl.europa.eu/RegData/etudes/STUD/2015/563401/IPOL_STU(2015)563401_EN.p $\underline{\mathrm{df}}$

European Parliament and the Council (2013), "Regulation (EU) No 1299/2013 of the European Parliament and of the Council of 17 December 2013 on specific provisions for the support from the 
European Regional Development Fund to the European territorial cooperation goal", Official Journal of the European Union, L 347/259, 20 December 2013, available at:

http://ec.europa.eu/newsroom/dae/document.cfm?doc_id=5238

European Parliament and the Council (2013), "Regulation (EU) No 1302/2013 of the European Parliament and of the Council of 17 December 2013 amending Regulation (EC) No 1082/2006 on a European grouping of territorial cooperation (EGTC) as regards the clarification, simplification and improvement of the establishment and functioning of such groupings", Official Journal of the European Union, L 347/303, 20 December 2013, available at: http://www.mou.gr/elibrary/Regulation_1302_2013\%20EGTC.pdf

European Parliament and the Council (2013), "Regulation (EU) No 1303/2013 of the European Parliament and of the Council of 17 December 2013 laying down common provisions on the European Regional Development Fund, the European Social Fund, the Cohesion Fund, the European Agricultural Fund for Rural Development and the European Maritime and Fisheries Fund and laying down general provisions on the European Regional Development Fund, the European Social Fund, the Cohesion Fund and the European Maritime and Fisheries Fund and repealing Council Regulation (EC) No 1083/2006", Official Journal L 347/320, 20 December 2013, available at:

https://www.funduszeeuropejskie.gov.pl/media/10683/Regulation No 1303 of 2013 of the EP an d_of the_Council.pdf

European Parliament and the Council (2013), "Regulation (EU) No 1315/2013 of the European Parliament and of the Council of 11 December 2013 on Union guidelines for the development of the trans-European transport network and repealing Decision No 661/2010/EU, available at: http://publications.europa.eu/resource/cellar/4a254b05-6968-11e3-a7e401aa75ed71a1.0006.01/DOC 1

European Parliament and the Council (2013), "Regulation (EU) No 1316/2013 of the European Parliament and of the Council of 11 December 2013 establishing the Connecting Europe Facility, amending Regulation (EU) No 913/2010 and repealing Regulations (EC) No 680/2007 and (EC) No 67/2010", Official Journal of the European Union, L 348/129, 20 December 2013, available at: http://publications.europa.eu/resource/cellar/4a254b05-6968-11e3-a7e401aa75ed71a1.0006.01/DOC_1

European Parliament and the Council (2014), "Regulation (EU) No 231/2014 of the European Parliament and of the Council of 11 march 2014 - establishing an Instrument for Pre-accession Assistance (IPA II)", Official Journal of the European Union, L77/11, 15 March 2014, available at: https://ec.europa.eu/neighbourhoodenlargement/sites/near/files/pdf/financial_assistance/ipa/2014/231-2014_ipa-2-reg.pdf

EUSAIR (2018a), "About EUSAIR", EU Strategy for the Adriatic-Ionian Region, available: http://www.adriatic-ionian.eu/about/the-adriatic-ionian-region

EUSAIR (2018b), "Slovenia Presenting Achievements of the EU Macro-Regional Processes at the $8^{\text {th }}$ World Water Forum”, EUSAIR, available: https://www.adriatic-ionian.eu/2018/03/25/sloveniapresenting-achievements-within-the-eu-macro-regional-processes-at-the-8th-world-water-forum-inbrasilia/

EUSAIR (2017), "Working paper regarding the establishment of a sustained dialogue between the EUSAIR and the ESIF Programmes. Labelling and funding EUSAIR Projects", January 2017. 
EUSAIR (2016), "Dubrovnik Declaration", First EUSAIR Forum, 12 May, 2016, Dubrovnik, Croatia, available:

http://ec.europa.eu/regional_policy/sources/conferences/adriat_ionian/2016/dubvrovniK_dec1005201 6.pdf

EUSAIR (2015), Rules of Procedure, Governing Board for the EU Strategy for the Adriatic and Ionian Region adopted on 10 July 2015

EUSAIR (2014), "Towards a streamlined governance and management architecture for the EUSAIR", Attached Working Paper, EUSAIR National Coordinators and European Commission, Brussels, Belgium, available:

http://ec.europa.eu/regional_policy/sources/cooperate/adriat_ionian/pdf/joint_statement_governance_ en.pdf

EUSAIR Facility Point (2018 - unpublished), "EUSAIR in its Full Power: Final Report on First Capacity Building Event”, Kobarid 27-28 March 2018, EUSAIR Facility Point, Slovenia.

EUSBSR (2017a), "Macro-regional strategies - what's in it for Cohesion Policy?, presentation", EU Strategy for the Baltic Sea Region, 8th Annual Forum in Berlin, 13/6/2017, https://www.balticsearegion-strategy.eu/8th-annual-forum/programme/16-8th-annual-forum/seminar-information/590847macro-regional-strategies-and-their-links-with-cohesion-policy

EUSBSR (2017b), "BSN-EAFRD network", presentation, available at: https://www.balticsea-regionstrategy.eu/attachments/article/590918/BSN-EAFRD\%20presentation\%202017.pdf

EUSBSR (2013), "Roles and responsibilities of the Implementing stakeholders of the EUSBSR and a flagship project concept", working document, EU Strategy for the Baltic Sea Region, January 2013, available at: https://www.balticsea-regionstrategy.eu/attachments/article/590645/EUSBSR\%20roles\%20and\%20responsibilities.pdf

EUSDR (2014), "Priority Area 10 - Stepping up institutional capacity and cooperation: Governance, Funding, Civil Society", European Union Strategy for the Danube Region, available at: https://www.danubecapacitycooperation.eu/uploads/files/01_EUSDR_PA10_implementation_report_30062014.pdf

EUSDR (2016), "European Strategy for Danube Region Strategic Projects: Concept Paper - Final", available at: https://www.danuberegion.eu/attachments/article/616561/Strategic\%20projects FINAL.pdf

EUSDR (2018), "TAF-DRP - What is TAF-DRP? " Danube Region Strategy official website, available at: https://www.danube-capacitycooperation.eu/taf-drp

Firbas I., Alignment of Partnership Agreement 2014-2020 funds with macro-regional strategies presentation, 'Dialogue' meeting ESIF - EUSAIR, Athens, 5 October 2016

Forsling, N. (2017), "ERDF MA-network welcoming new topics for collaboration", EU Strategy for the Baltic Sea Region, 01/12/2017, http://www.pa-innovation.eu/news/erdf-ma-network-welcoming-newtopics-for-collaboration/

Gnamus, A., F. B. Hegyi, and S. E. Perez (2014), "Developing Danube R\&I Projects across Borders How to Make the Joint Use of EU-Funds a Reality?" JRC Technical Reports - S3 Policy Brief, Series 
No. 10/2014, available:

http://s3platform.jrc.ec.europa.eu/documents/20182/114990/JRC91447_Developing_Danube_R\%26I _Projects.pdf/f7682b44-a87f-4c25-bd1c-1200f93ed72e

Interact (2017a), "Making the most of macro-regions: Trends. Analysis. Recommendations", 2017, available at: http://www.adriatic-

ionian.eu/attachments/article/616559/Interact Making the most of macro-regions eBook.pdf

Interact (2017b), "Added value of macro-regional strategies, Project and programme perspective" - Final report of the study, February 2017, available at:

http://s3platform.jrc.ec.europa.eu/documents/20182/198909/Added+value+of+the+macroregional+strategies+for+projects+and+programmes/adefa20c-8b5d-48c8-8690-1e8fdd2570cc

Interact (2015), "Cooperation methods and tools applied by European Structural and Investment Funds programmes for 2014-2020 to support implementation of the European Union Strategy for the Baltic Sea Region", First interim report - Task 1 - Description of selected ESI Funds operational programmes, May 2015, available at: https://www.balticsea-regionstrategy.eu/attachments/article/590702/Final\%20Interim\%20Report\%20$\% 20$ Cooperation $\% 20$ methods $\% 20$ and $\% 20$ tools $\% 20$ to $\% 20$ support $\% 20$ the $\% 20$ EUSBSR.pdf

Interact (2015), "Cooperation methods and tools applied by European Structural and Investment Funds programmes for 2014-2020 to support implementation of the European Union Strategy for the Baltic Sea Region", Final report, June 2015, available at: http://www.interact-eu.net/download/file/fid/5154

Joint Research Centre of the European Commission (2014), "Developing Danube R\&I Projects across Borders - How to Make the Joint Use of EU-Funds a Reality?, JRC Technical Reports" - S3 Policy brief series no. 10, September 2014, available at:

http://s3platform.jrc.ec.europa.eu/documents/20182/114990/JRC91447_Developing_Danube_R\%26I _Projects.pdf/f7682b44-a87f-4c25-bd1c-1200f93ed72e

Med National Contact Point (2014), "La valutazione del contributo dei progetti MED alla programmazione regionale in Italia - i risultati finali della sperimentazione", Giugno 2014, available at: http://territorio.regione.emilia-romagna.it/sviluppo-coesione-e-cooperazioneterritoriale/cooperazione-territoriale-europea/approfondimenti/la-valutazione-del-contributo-deiprogetti-med-alla-programmazione-regionale-in-italia/at_download/file/Relazione\%20MED2.pdf

OECD (2017a), "Survey on Multi-level governance for effective implementation of the EU Strategy for the Adriatic and Ionian Region", Questionnaire: Preliminary overview in each EUSAIR Country, April 2017.

OECD (2017b) Survey, "OECD/EUSAIR Questionnaire: Results and Highlights", slide presentation, April 2017.

OECD Case Studies (2017)

-OECD, EUSAIR Case study of multi-level governance and cross-sectoral coordination in Albania, November 2017

- OECD, EUSAIR Case study of multi-level governance and cross-sectoral coordination in Croatia, December 2017 
- OECD, EUSAIR Case study of multi-level governance and cross-sectoral coordination in Bosnia \& Herzegovina, December 2017

- OECD, EUSAIR Case study of multi-level governance and cross-sectoral coordination in Greece, November 2017

- OECD, EUSAIR Case study of multi-level governance and cross-sectoral coordination in Italy, December 2017

- OECD, EUSAIR Case study of multi-level governance and cross-sectoral coordination in Montenegro, December 2017

- OECD, EUSAIR Case study of multi-level governance and cross-sectoral coordination in Serbia, October 2017

- OECD, EUSAIR Case study of multi-level governance and cross-sectoral coordination in Slovenia, December 2017

OECD (2016), "OECD Regional Outlook 2016: Productive Regions for Inclusive Societies", Part IV, Country notes, OECD Publishing, Paris, http://dx.doi.org/10.1787/9789264260245-en.

Regional Cooperation Council (2017), "South East Europe 2020, Annual Report on implementation for 2017", July 2017, available at: https://www.rcc.int/download/docs/17-06-19\%20ARI\%202017\%20\%20Final.pdf/01afc96196d329dbf553ff9a4457fadd.pdf

Regional Cooperation Council (2013), "South East Europe (SEE) 2020 Strategy - Jobs and Prosperity in a European Perspective", November 2013, available at: http://seehn.org/web/wpcontent/uploads/2014/07/SEE2020-Strategy.pdf

Republic of Serbia (2015), "Single project pipeline - tool for concentrated economic development", presentation, Ministry of Construction, Transport and Infrastructure, Pristina, 25 March 2015, available at:

http://www.mgsi.gov.rs/sites/default/files/Serbian\%20Single\%20Project\%20Pipeline\%2024.03.2015. ppt

Republic of Serbia (2015), "Single project pipeline", bilateral screening, Chapter 22 - Regional Policy and Coordination of Structural Instruments, presentation, Brussels 29/01/2015, available at: http://www.eupregovori.rs/files/File/documents/skrining/bilateralni/prezentacije/pg22/08_Single_Project_Pipeline.p $\underline{\mathrm{df}}$

Slovenia National Coordinator (2017), "EUSAIR TSG 3 workshop proceedings: "How to translate synergies between MSP and ICZM into concrete projects" including "Interpillar draft matrix", Mediterranean Coast and EU Macro-regional Strategies Week, Slovenia, 20-23 September 2017

Svenska ESF-rådet (Swedish ESF Council) (n/d), "Baltic Sea Network", official website, https://www.esf.se/en/Sidhuvud/The-swedish-ESF-council/Baltic-Sea-Network/

Tillväxtverket (Sweden Agency for Economic and Regional Growth) (2016), The Baltic Sea Region Strategy for Beginners, Tillväxtverket, Stockholm, Sweden, available: https://tillvaxtverket.se/vara- 
tjanster/publikationer/publikationer-2016/2016-10-27-the-baltic-sea-region-strategy-forbeginners.html

Tillväxtverket (Swedish Agency for Economic and Regional Growth) (2014), "Macro Regional Strategies in the ESI Operational Programmes 2014-2020 - proposal for a Transnational Cooperation Component to support the implementation of the EU Strategy for the Baltic Sea Region", Concept Paper, updated on 20 January 2014, available at: https://www.balticsea-region-

strategy.eu/images/olddocs/20140120+SE+concept+paper+Cooperation+in+ESI Updated.pdf 
Annex A. A comparative table of actors involved by country and by pillar

\begin{tabular}{|c|c|c|c|c|c|c|c|c|c|c|}
\hline $\begin{array}{l}\text { Involvement in } \\
\text { EUSAIR }\end{array}$ & \multicolumn{3}{|c|}{ PILLAR 1 BLUE GROWTH } & \multicolumn{3}{|c|}{ PILLAR 2 CONNECTING THE REGION } & \multicolumn{2}{|c|}{$\begin{array}{c}\text { PILLAR } 3 \text { ENVIRONMENTAL } \\
\text { QUALITY }\end{array}$} & \multicolumn{2}{|c|}{$\begin{array}{c}\text { PILLAR } 4 \text { SUSTAINABLE } \\
\text { TOURISM }\end{array}$} \\
\hline $\begin{array}{l}\text { Country/National } \\
\text { government level } \\
\text { Subnational government } \\
\text { level } \\
\text { Non-government } \\
\text { Stakeholders }\end{array}$ & $\begin{array}{l}\text { Blue } \\
\text { technology }\end{array}$ & $\begin{array}{l}\text { Fisheries \& } \\
\text { aqua-culture }\end{array}$ & $\begin{array}{l}\text { Maritime \& } \\
\text { marine } \\
\text { governance }\end{array}$ & $\begin{array}{l}\text { Maritime } \\
\text { transport }\end{array}$ & $\begin{array}{l}\text { Intermodal } \\
\text { connection }\end{array}$ & Energy networks & $\begin{array}{l}\text { Marine } \\
\text { environment }\end{array}$ & $\begin{array}{l}\text { Transnational } \\
\text { territorial } \\
\text { habitats and } \\
\text { biodiversity }\end{array}$ & $\begin{array}{l}\text { Diversified } \\
\text { tourism offer }\end{array}$ & $\begin{array}{l}\text { Sustainable } \\
\& \text { diversified } \\
\text { tourism } \\
\text { management }\end{array}$ \\
\hline \multicolumn{11}{|l|}{ ALBANIA } \\
\hline Government Level & \multicolumn{3}{|c|}{$\begin{array}{c}\text { Ministry of Agriculture and Rural Development } \\
\text { Ministry of Infrastructure and Energy }\end{array}$} & \multicolumn{3}{|c|}{ Ministry of Infrastructure and Energy } & \multicolumn{2}{|c|}{$\begin{array}{c}\text { Ministry of Environment and } \\
\text { Tourism }\end{array}$} & \multicolumn{2}{|c|}{$\begin{array}{c}\text { Ministry of Environment and } \\
\text { Tourism }\end{array}$} \\
\hline \multicolumn{11}{|l|}{ Regional Level } \\
\hline \multicolumn{11}{|l|}{ Municipal/Local Level } \\
\hline $\begin{array}{l}\text { Non-government } \\
\text { organisations }\end{array}$ & & & & & & & $\begin{array}{c}\text { NGOs } \\
\text { Civil Society } \\
\text { Organisations }\end{array}$ & & \multicolumn{2}{|c|}{$\begin{array}{c}\text { NGOs } \\
\text { Civil Society Organisations }\end{array}$} \\
\hline \multicolumn{11}{|l|}{ BOSNIA \& HERZEGOVINA } \\
\hline $\begin{array}{l}\text { National (State) } \\
\text { Government Level }\end{array}$ & \multicolumn{3}{|c|}{$\begin{array}{c}\text { Ministry of Foreign Trade and Economic Relations } \\
\text { of BiH } \\
\text { (Sector for Agriculture, Food, Forestry and Rural } \\
\text { Development) }\end{array}$} & \multicolumn{2}{|c|}{$\begin{array}{l}\text { Ministry of Communications } \\
\text { and Transport of BiH } \\
\text { Ministry of Foreign Trade and } \\
\text { Economic relations of BiH }\end{array}$} & $\begin{array}{l}\text { Ministry of } \\
\text { Foreign Trade } \\
\text { and Economic } \\
\text { Relations of BiH }\end{array}$ & \multicolumn{2}{|c|}{$\begin{array}{l}\text { Ministry of Foreign Trade and } \\
\text { Economic relations of BiH }\end{array}$} & \multicolumn{2}{|c|}{$\begin{array}{c}\text { Ministry of Foreign Trade and } \\
\text { Economic Relations of BiH }\end{array}$} \\
\hline
\end{tabular}


56 EUSAIR SYNTHESIS REPORT

\begin{tabular}{|c|c|c|c|c|c|c|c|}
\hline $\begin{array}{l}\text { Entity Government } \\
\text { Level }\end{array}$ & \multicolumn{3}{|c|}{ Ministry of Agriculture, Water and Forestry } & $\begin{array}{l}\text { Federal Ministry of Transport } \\
\text { and Communications } \\
\text { Ministry of Transport of RS }\end{array}$ & $\begin{array}{l}\text { Federal Ministry } \\
\text { of Energy, Mining } \\
\text { and Industry } \\
\text { Ministry of } \\
\text { Industry, Energy } \\
\text { and Mining of RS }\end{array}$ & $\begin{array}{c}\text { Ministry of Environment and } \\
\text { Tourism of Federation of BiH } \\
\text { Ministry of Physical planning, } \\
\text { Construction and Ecology of RS } \\
\text { Environmental Protection } \\
\text { Agencies } \\
\end{array}$ & $\begin{array}{c}\text { Federal Ministry of } \\
\text { Environment and Tourism } \\
\text { Ministry of Trade and Tourism } \\
\text { of RS }\end{array}$ \\
\hline Cantonal Level & \multicolumn{3}{|c|}{$\begin{array}{l}\text { Ministry of Agriculture, Water Management and } \\
\text { Forestry of Herzegovina-Neretva Canton }\end{array}$} & Ministry of Transport & & & \\
\hline \multicolumn{8}{|l|}{ Municipal/Local Level } \\
\hline \multirow{2}{*}{\multicolumn{8}{|c|}{$\begin{array}{l}\text { Non-government } \\
\text { organisations } \\
\text { CROATIA }\end{array}$}} \\
\hline & & & & & & & \\
\hline Government Level & $\begin{array}{l}\text { Ministry of } \\
\text { Economy, } \\
\text { Entrepreneurship } \\
\text { \& Crafts }\end{array}$ & $\begin{array}{c}\text { Ministry of } \\
\text { Agriculture } \\
\& \\
\text { Fisheries }\end{array}$ & $\begin{array}{l}\text { Ministry of } \\
\text { Maritime } \\
\text { Affairs, } \\
\text { Transport \& } \\
\text { Infrastructure } \\
\\
\text { Ministry of } \\
\text { Environmental } \\
\text { Protection \& } \\
\text { Energy } \\
\text { Ministry of } \\
\text { Construction } \\
\text { and Spatial } \\
\text { Planning }\end{array}$ & $\begin{array}{l}\text { Ministry of Maritime Affairs, } \\
\text { Transport \& Infrastructure* }\end{array}$ & $\begin{array}{l}\text { Ministry of } \\
\text { Environmental } \\
\text { Protection \& } \\
\text { Energy } \\
\text { Ministry of } \\
\text { Maritime Affairs, } \\
\text { Transport \& } \\
\text { Infrastructure }\end{array}$ & $\begin{array}{l}\text { Ministry of Environmental } \\
\text { Protection \& Energy }\end{array}$ & Ministry of Tourism \\
\hline \multicolumn{8}{|l|}{ Regional Level } \\
\hline \multicolumn{8}{|l|}{ Municipal/Local Level } \\
\hline $\begin{array}{l}\text { Non-government } \\
\text { organisations }\end{array}$ & & & & & & & \\
\hline
\end{tabular}




\begin{tabular}{|c|c|c|c|c|c|}
\hline \multicolumn{6}{|l|}{ GREECE } \\
\hline Government Level & $\begin{array}{l}\text { Ministry of Agriculture and Food } \\
\text { Special Services for Fisheries and Maritime OP }\end{array}$ & $\begin{array}{l}\text { Ministry of Infrastructure and } \\
\text { Transport: } \\
\text { Directorate General of } \\
\text { Outward and Security Policy } \\
\text { - Unit of International and } \\
\text { European Issues for } \\
\text { Transport }\end{array}$ & $\begin{array}{c}\text { Ministry of } \\
\text { Environment and } \\
\text { Energy: } \\
\text { Directorate of } \\
\text { International and } \\
\text { European } \\
\text { Activities, Dep.t } \\
\text { of European and } \\
\text { International } \\
\text { Energy Affairs }\end{array}$ & $\begin{array}{l}\text { Ministry of Environment and } \\
\text { Energy: } \\
\text { Directorate of International and } \\
\text { European Activities }\end{array}$ & $\begin{array}{l}\text { Ministry of Tourism: } \\
\text { Directorate of Strategic } \\
\text { Planning } \\
\text { Ministry of Culture and Sports }\end{array}$ \\
\hline Regional Level & Regional Government Authorities & \multicolumn{2}{|c|}{ Regional Government Authorities } & $\begin{array}{l}\text { Regional Government } \\
\text { Authorities }\end{array}$ & $\begin{array}{l}\text { Regional Government } \\
\text { Authorities }\end{array}$ \\
\hline \multicolumn{6}{|l|}{ Municipal/Local Level } \\
\hline $\begin{array}{l}\text { Non-government } \\
\text { organisations }\end{array}$ & Academia and Research Centres & \multicolumn{2}{|c|}{$\begin{array}{c}\text { Academia and Research Centres } \\
\text { Institute of Communication and Computer Systems } \\
\text { (ICCS) } \\
\text { Centre For Research and Technology (CERTH)- } \\
\text { Hellenic Institute of Transport (HIT) }\end{array}$} & $\begin{array}{l}\text { Academia and Research } \\
\text { Centres, NGOs, CSOs }\end{array}$ & \\
\hline \multicolumn{6}{|c|}{ 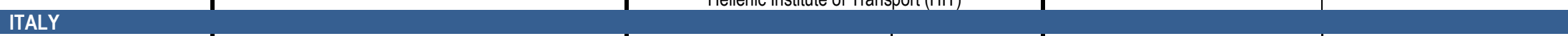 } \\
\hline Government Level & $\begin{array}{l}\text { Ministry of Agriculture Resources, Food and } \\
\text { Forestry }\end{array}$ & $\begin{array}{l}\text { Ministry of Infrastructure and } \\
\text { Transportation }\end{array}$ & $\begin{array}{c}\text { Ministry of } \\
\text { Economic } \\
\text { Development }\end{array}$ & Ministry of Environment & $\begin{array}{l}\text { Ministry of Cultural Resources } \\
\text { and Tourism }\end{array}$ \\
\hline Regional Level & $\begin{array}{c}\text { Veneto Region and Region of Molise* } \\
\text { Other Regions }\end{array}$ & \multicolumn{2}{|c|}{$\begin{array}{c}\begin{array}{c}\text { Friuli Venezia Giulia and Abruzzo Regions* } \\
\text { Other Regions }\end{array} \\
\end{array}$} & $\begin{array}{l}\text { Emilia Romagna and Umbria* } \\
\text { Other Regions }\end{array}$ & $\begin{array}{l}\text { Puglia and Sicilian Region * } \\
\text { Other Regions }\end{array}$ \\
\hline \multicolumn{6}{|l|}{ Municipal/Local Level } \\
\hline $\begin{array}{l}\text { Non-government } \\
\text { organisations }\end{array}$ & & & & & \\
\hline
\end{tabular}


$\mathbf{5 8} \mid$ EUSAIR SYNTHESIS REPORT

\begin{tabular}{|c|c|c|c|c|c|c|}
\hline \multicolumn{7}{|l|}{ MONTENEGRO } \\
\hline Government Level & $\begin{array}{l}\text { Ministry of Agriculture and } \\
\text { Rural Development } \\
\text { (Fisheries) }\end{array}$ & $\begin{array}{c}\text { Ministry of } \\
\text { Sustainable } \\
\text { Development and } \\
\text { Tourism } \\
\text { Ministry of } \\
\text { Transport and } \\
\text { Maritime Affairs } \\
\text { Montenegrin Port } \\
\text { Authority }\end{array}$ & $\begin{array}{l}\text { Ministry of Transport and } \\
\text { Maritime Affairs } \\
\text { Montenegrin Port Authority }\end{array}$ & $\begin{array}{l}\text { Ministry of } \\
\text { Economy }\end{array}$ & $\begin{array}{l}\text { Ministry of Sustainable } \\
\text { Development and Tourism } \\
\text { Ministry of Transport and } \\
\text { Maritime Affairs }\end{array}$ & $\begin{array}{c}\text { Ministry of Sustainable } \\
\text { Development and Tourism } \\
\text { Ministry of Culture } \\
\text { National Tourism Organization }\end{array}$ \\
\hline \multicolumn{7}{|l|}{ Regional Level } \\
\hline \multicolumn{7}{|l|}{ Municipal Level } \\
\hline $\begin{array}{l}\text { Non-government } \\
\text { organisations }\end{array}$ & \multicolumn{2}{|l|}{ Institute for Marine Biology } & & & Institute for Marine Biology & \\
\hline \multicolumn{7}{|l|}{ SERBIA } \\
\hline Government Level & \multicolumn{2}{|c|}{ Ministry of Economy } & $\begin{array}{l}\text { Ministry of Construction, } \\
\text { Transport and Infrastructure }\end{array}$ & $\begin{array}{c}\text { Ministry of } \\
\text { Mining and } \\
\text { Energy }\end{array}$ & $\begin{array}{l}\text { Ministry of Environmental } \\
\text { Protection }\end{array}$ & $\begin{array}{l}\text { Ministry of Trade, Tourism and } \\
\text { Telecommunications } \\
\text { Ministry of Culture and } \\
\text { Information }\end{array}$ \\
\hline \multicolumn{7}{|l|}{ Regional Level } \\
\hline \multicolumn{7}{|l|}{ Municipal Level } \\
\hline $\begin{array}{l}\text { Non-government } \\
\text { organisations }\end{array}$ & $\begin{array}{c}\text { Academia, } \\
\text { Research } \\
\text { Centres }\end{array}$ & & & & $\begin{array}{l}\text { Academia, Research Centres, } \\
\text { civil society organisations }\end{array}$ & $\begin{array}{l}\text { Academia, civil society } \\
\text { organisations }\end{array}$ \\
\hline
\end{tabular}




\begin{tabular}{|c|c|c|c|c|c|}
\hline \multicolumn{6}{|l|}{ SLOVENIA } \\
\hline Government Level & $\begin{array}{l}\text { Ministry of Agriculture Forestry and Food } \\
\text { Ministry of Health } \\
\text { Ministry of the Environment and Spatial Planning }\end{array}$ & $\begin{array}{l}\text { Ministry of Infrastructure } \\
\text { Ministry of the Environment } \\
\text { and Spatial Planning }\end{array}$ & $\begin{array}{l}\text { Ministry of } \\
\text { Infrastructure } \\
\text { Ministry of the } \\
\text { Environment } \\
\text { and Spatial } \\
\text { Planning }\end{array}$ & $\begin{array}{l}\text { Ministry of the Environment and } \\
\text { Spatial Planning } \\
\text { Ministry of Defence } \\
\text { Administration for Civil } \\
\text { Protection and Disaster Relief } \\
\text { Ministry of Culture } \\
\text { Institute for the Protection of } \\
\text { Cultural Heritage of Slovenia, } \\
\text { Regional Office Piran }\end{array}$ & $\begin{array}{c}\text { Ministry Economic } \\
\text { Development and Technology } \\
\text { Ministry of Culture }\end{array}$ \\
\hline \multicolumn{6}{|l|}{ Regional Level } \\
\hline \multicolumn{6}{|l|}{ Municipal Level } \\
\hline $\begin{array}{l}\text { Non-government } \\
\text { organisations }\end{array}$ & & & & & \\
\hline
\end{tabular}

Note:

* Regional Focal and deputy focal points 
60 $\mid$ OECD NATIONAL EUSAIR MULTI-LEVEL GOVERNANCE SELF-ASSESSMENT TOOL

EUSAIR SYNTHESIS REPORT @ OECD 2019 